Federal Reserve Bank of Minneapolis

Research Department Staff Report 367

January 2006

\title{
Temptation and Self-Control: Some Evidence and Applications ${ }^{\dagger}$
}

\author{
Kevin X.D. Huang \\ Federal Reserve Bank of Philadelphia \\ Zheng Liu \\ Emory University \\ and Federal Reserve Bank of Minneapolis
}

Qi Zhu

Emory University

\begin{abstract}
This paper studies the empirical relevance of temptation and self-control using household-level data from the Consumer Expenditure Survey. We estimate an infinite-horizon consumptionsavings model that allows, but does not require, temptation and self-control in preferences. To help identify the presence of temptation, we exploit an implication of the theory that a tempted individual has a preference for commitment. In the presence of temptation, the cross-sectional distribution of the wealth-consumption ratio, in addition to that of consumption growth, becomes a determinant of the asset-pricing kernel, and the importance of this additional pricing factor depends on the strength of temptation. The estimates that we obtain provide statistical evidence supporting the presence of temptation. Based on our estimates, we explore some quantitative implications of this class of preferences on equity premium and on the welfare cost of business cycles.
\end{abstract}

† We are grateful to Narayana Kocherlakota and Luigi Pistaferri for helpful suggestions, and to seminar participants at the Federal Reserve Bank, the University of Minnesota, the SED 2005 Annual Meeting, and the Midwest Macro 2005 Annual Meeting for comments. Liu thanks the Federal Reserve Bank of Minneapolis and the University of Minnesota for their hospitality. The views expressed herein are those of the authors and do not necessarily reflect the views of the Federal Reserve Bank of Philadelphia, the Federal Reserve Bank of Minneapolis, or the Federal Reserve System. 


\section{Introduction}

Experimental studies find that, as time passes, subjects exhibit "preference reversals" in that they would prefer the larger and later of two prizes when both are offered in the distant future, whereas they would choose the smaller and earlier award if both prizes are drawn instantaneously (e.g., Loewenstein, 1996; Rabin, 1998). A manifestation of this behavior is that, when planning for the long run, one intends to meet deadlines, exercise regularly, and eat healthy; but the short-run behavior is rarely consistent with the long-run plan. ${ }^{1}$ One interpretation of this kind of behavior is that decision makers discount future preferences hyperbolically rather than exponentially (e.g., Laibson, 1994, 1996, 1997; Harris and Laibson, 2001; Angeletos et al., 2001). A main critique of this interpretation is that the underlying preferences are time-inconsistent: today's self would be different from tomorrow's self, and the "selves" in different time periods often have conflicting goals. The time inconsistency in preferences often complicates studies of public policy issues, since it is difficult to find an agreeable social welfare objective. ${ }^{2}$

An alternative interpretation of the behavioral observations builds on axiomatic foundations for preferences that allow for temptation and self-control. This specification allows one to capture the potential conflict between an agent's ex ante long-run ranking of options and her ex post short-run urges in a rational and time-consistent framework. A typical agent faces temptation in each period of time, and she exercises costly self-control efforts to resist the temptation. Thus, she might be better off if facing a smaller opportunity set that excludes the ex ante inferior but ex post tempting alternatives. What makes this approach different from the hyperbolic-discounting approach is that, at any point in time, the individual would not regret an earlier decision, since she has done her best resisting temptations in every period. In other words, the resulting preference representation is time-consistent, which makes it easier to study public policy issues than if timeinconsistent preferences were used (e.g., Gul and Pesendorfer, 2001, 2004a, 2004b, 2005a).

Another advantage of the axiom-based approach is that it allows for a recursive representation of preferences: one can reduce an infinite-horizon planning problem into a recursive, two-period problem, making theoretical characterization and solution much easier. This is perhaps an important reason why this class of preferences has gained popularity since its initial theoretical development by Gul and Pesendorfer a few years ago. For example, Krusell, Kuruşçu, and Smith

\footnotetext{
${ }^{1}$ For recent evidence on temptation and the lack of self-control in consumption-savings decision based on a survey of TIAA-CREF participants, see Ameriks et al. (2004). Their survey also indicates that self-control is linked to "conscientiousness" in planning, an idea that takes its root in Strotz (1956) and Peleg and Yaari (1973).

${ }^{2}$ For some related issues concerning this type of preferences, see, for example, Jagannathan and Kocherlakota (1996), Rubinstein (2003), Krusell and Smith (2003), and Gul and Pesendorfer (2004a).
} 
(2002) and DeJong and Ripoll (2003) apply the theory with self-control preferences to asset pricing, Krusell, Kuruşçu, and Smith (2003) to taxation, Ameriks et al. (2004) to survey designs, Gul and Pesendorfer (2004a, 2004b) to consumption-savings decisions and welfare, and Gul and Pesendorfer (2005b) to harmful addiction. ${ }^{3}$

Applied work in this rapidly growing literature has encountered a short supply of empirical evidence that is needed for quantifying the strength of temptation and self-control, or the lack thereof, which is crucial for assessing the significance of their effects in the areas of greatest economic importance. Researchers in this area have thus far relied on calibration of key parameters based on aggregate data (e.g., Laibson, Repetto, and Tobacman, 1998; Krusell, Kuruş̧̧u, and Smith, 2002). As pointed out by Krusell, Kuruşçu, and Smith (2002), the "results are hard to judge quantitatively since we do not have any independent information regarding the strength or nature of the possible savings urges among investors."

The current paper intends to fill this gap by estimating the quantitative strength of temptation and self-control. For this purpose, we construct an infinite-horizon consumption-savings model that allows for, but does not require, temptation and self-control in preferences. Since our model nests the standard consumption-savings model without temptation as a special case, testing the statistical significance of the presence of temptation boils down to a model-restriction test. We implement this test by first estimating an unrestricted model that allows for temptation using the generalized method of moments (GMM), and then a restricted model that corresponds to the standard model without temptation. It is then straightforward to construct a Wald statistic to test the null hypothesis of the absence of temptation and self-control.

Our work shares a similar goal as DeJong and Ripoll (2003), who estimate the strength of temptation based on a version of the Lucas (1978) model of asset pricing. A main difference is that we use household-level data from the Consumer Expenditure Survey (CEX) to build a pseudopanel with synthetic birth-year cohorts for our estimation, whereas DeJong and Ripoll rely on aggregate time series data. ${ }^{4}$ From this perspective, our work is perhaps more closely related to that by Paserman (2004), Fang and Silverman (2004), and Laibson, Repetto, and Tobacman (2004), who all employ panel or field data in estimating the quantitative effects of self-control problems under preference specifications with hyperbolic discounting.

The use of micro data in our estimation is essential for several reasons. First, it allows us to capture individual differences in the strength of temptation and self-control. This level of

\footnotetext{
${ }^{3}$ Related theoretical and applied work also includes Benhabib and Bisin (2005) and Bernheim and Rangel (2002), among others.

${ }^{4}$ The pseudo-panel approach that we use is proposed by Attanasio and Weber $(1989,1993,1995)$ in the spirit of Browning, Deaton, and Irish (1985), Deaton (1985), and Heckman and Robb (1985).
} 
heterogeneity is particularly useful for identifying the presence of temptation, since our model implies that an individual who is more susceptible to temptation would be more likely to hold commitment assets, as holding commitment assets helps reduce the cost of self control. ${ }^{5}$ Second, allowing for preference heterogeneity and idiosyncratic risks is essential, especially in the absence of a complete insurance market. Without complete insurance, estimating intertemporal Euler equations based on aggregate data would be problematic, since agents would be exposed to important uninsurable idiosyncratic risks. Third, as intertemporal Euler equations hold only for those individuals who participate in asset market transactions, using aggregate data may lead to inconsistent estimates of the parameters of interest as the limited-participation aspect would be ignored in the process of aggregation. ${ }^{6}$

In practice, we estimate jointly the elasticity of intertemporal substitution (EIS) and the temptation parameter using GMM in our baseline model. We parameterize the utility function to be consistent with balanced growth and recent evidence on the cointegrating relations between consumption, income, and wealth (e.g., Lettau and Ludvigson, 2001, 2004). We focus on estimating a log-linearized Euler equation, which is linear in parameters, based on pseudo-panel data constructed using the synthetic cohort approach. We try to control the aggregation process and deal with potential measurement errors in the individual level data. This is fundamentally the same approach taken by Vissing-Jorgensen (2002), among others, under the standard preferences without temptation.

As we allow for temptation and self-control, the cross-sectional distribution of wealth-consumption ratios, in addition to the cross-sectional distribution of consumption growth rates, becomes a determinant of the intertemporal marginal rate of substitution (IMRS) (also known as the assetpricing kernel or the stochastic discount factor), and the importance of this additional factor depends on the strength of temptation and self-control. The wealth-consumption ratio appears in the asset-pricing kernel because, if the individual agent succumbs to temptation, she would consume her entire income and accumulated (liquid) assets, which correspond to our definition of wealth. In other words, wealth is the "temptation consumption."

\footnotetext{
${ }^{5}$ Della Vigna and Paserman (2004) present evidence on cross-sectional variation in the level of self-control and show that it predicts cross-sectional variation in behaviors. Krusell, Kuruşçu, and Smith (2002) argue for the realism of differing degrees of temptation and self-control among consumers, and they demonstrate the potential significance of such heterogeneity in accounting for the high equity premium and low risk-free rate. See also Ameriks et al. (2004) for some evidence on the heterogeneity in the degree of temptation and self-control in a survey sample of TIAA-CREF participants.

${ }^{6}$ For some recent studies that emphasize the importance of idiosyncratic risks and limited participation, see Brav, Constantinides, and Geczy (2002), Cogley (2002), Vissing-Jorgensen (2002), and Jacobs and Wang (2004). For a survey of this literature, see Constantinides (2002).
} 
The estimates that we obtain provide statistical evidence supporting the existence of temptation and self-control in preferences. With reasonable precisions, we obtain a significant estimate of the strength of present-biased temptation, and we reject the null hypothesis of no temptation at common confidence levels.

To distinguish self-control preferences from other classes of preferences such as habit formation (e.g., Constantinides, 1990; Campbell and Cochrane, 1999) or non-expected utility (e.g., Epstein and Zin $(1989,1991)$, we exploit an implication of self-control preferences that an individual who is more susceptible to temptation would be more likely to hold commitment assets, which are assets that cannot be easily re-traded (e.g., Gul and Pesendorfer, 2004b). To implement this idea, we include in our estimation equation an interaction term between the wealth-consumption ratio and an education dummy. The education dummy takes a value of one if the underlying individual has received 16 or more years of schooling, and zero otherwise. Since education can be viewed as a form of commitment asset (e.g., Kocherlakota, 2001), we should expect those individuals with higher levels of education to also have a larger temptation parameter. Indeed, this is borne out by our estimation. Further, we find evidence that individuals with higher education levels are also more likely to contribute to pensions. Since pensions can be reasonably viewed as another form of commitment assets, this evidence lends further support to the presence of temptation and self-control in preferences.

To illustrate the potential applications of the temptation and self-control preferences, we explore how the presence of temptation, with a reasonable magnitude as suggested by our estimates, can affect equity premium and calculations of the welfare costs of business cycles. There, we find that the presence of temptation in itself does not explain the equity premium puzzle. But more encouragingly, we obtain some welfare results that are somewhat surprising yet quite intuitive.

The rest of the paper is organized in the following order. Section 2 presents an infinite-horizon consumption-savings model that allows for temptation and self-control, with the utility function parameterized to be consistent with balanced growth and the cointegration properties between consumption, income, and wealth. Section 3 describes the data construction and aggregation approach. Section 4 explains our estimation strategies. Section 5 reports the estimation results and offers some discussions. Section 6 discusses some quantitative implications of the temptation preferences in light of our estimation results. Section 7 concludes. 


\section{A Consumption-Savings Model with Temptation and Self-Control}

In this section, we first consider an infinite-horizon consumption-savings problem that allows, but does not require, the possibility of temptation and self-control in preferences, as formalized by Gul and Pesendorfer (GP) (2001, 2004a, 2004b). We then characterize the stochastic discount factor $(\mathrm{SDF})$ in the presence of temptation and dynamic self-control.

\subsection{An Axiom-Based Representation for Self-Control Preferences}

Gul and Pesendorfer (2001, 2004a) consider decision problems by agents who are susceptible to temptations in the sense that ex ante inferior choice may tempt the decision maker ex post. They develop an axiom-based and time-consistent representation of self-control preferences that identifies the decision maker's commitment ranking, temptation ranking, and cost of self-control. According to their definition, "an agent has a preference for commitment if she strictly prefers a subset of alternatives to the set itself; she has self-control if she resists temptation and chooses an option with higher ex ante utility." They show that, to obtain a representation for the self-control preferences, it is necessary, in addition to the usual axioms (completeness, transitivity, continuity, and independence), to introduce a new axiom called "set betweenness," which states that $A \succeq B$ implies $A \succeq A \bigcup B \succeq B$ for any choice sets $A$ and $B$. Under this axiom, an option that is not chosen ex post may affect the decision maker's utility at the time of decision because it presents temptation; and temptation is costly since an alternative that is not chosen cannot increase the decision maker's utility.

Under these axioms, GP (2001) show that a representation for the self-control preferences takes the form

$$
W(A)=\max _{x \in A} u(x)+v(x)-\max _{y \in A} v(y),
$$

where both $u$ and $v$ are von Neumann-Morgenstern utility functions over lotteries and $W(A)$ is the utility representation of self-control preferences over the choice set $A$. The functions $u$ and $v$ describe the agent's commitment ranking and temptation ranking, respectively. The term $\max _{y \in A} v(y)-v(x)$ is non-negative for all $x \in A$, and it represents the utility cost of self-control.

\subsection{The Infinite-Horizon Consumption-Savings Problem}

Consider now a consumption-savings problem in an infinite-horizon economy with a large number $(H)$ of households, who face idiosyncratic risks and incomplete insurance. The households have access to an asset market, where they trade $I$ types of assets, including a risk-free asset. Let $c_{t}^{h}$ 
denote consumption by household $h, e_{t}^{h}$ his endowment, and $\mathbf{b}_{t}^{h}=\left(b_{t}^{1 h}, b_{t}^{2 h}, \ldots, b_{t}^{I h}\right)^{\prime}$ his assetholding position at the beginning of period $t$, for $h \in\{1,2, \ldots, H\}$. Let $q_{t}^{i}$ and $d_{t}^{i}$ denote the price and the dividend payoff of asset $i \in\{1, \ldots, I\}$ in period $t$. Each household takes as given the asset prices and dividends, his endowment, and current asset positions, and chooses consumption and new asset positions to maximize his expected lifetime discounted utility. In the decision problem, a household faces a temptation to consume all his wealth that consists of current endowment and the market value of his current assets. He may exert costly efforts to resist such temptations. As shown by GP (2004a), an infinite-horizon consumption planning problem, like the one described here, can be formulated in a recursive form. Denote by $z(\mathbf{b})$ the infinite-horizon planning problem when the current asset position is $\mathbf{b}$. The decision problem for a generic household is then described by the dynamic programming problem

$$
W(z(\mathbf{b}))=\max _{c, \tilde{\mathbf{b}}}\{u(c)+v(c)+\delta \mathrm{E} W(z(\tilde{\mathbf{b}}))-v(w)\},
$$

subject to the budget constraint

$$
\sum_{i=1}^{I} q^{i} \tilde{b}^{i}=e+\sum_{i=1}^{I}\left(q^{i}+d_{i}\right) b^{i}-c,
$$

where $u$ and $v$ are von Neumann-Morgenstern utility functions, $\delta \in(0,1)$ is a discount factor, and $\mathrm{E}$ is an expectation operator, and the tilde terms denote variables in the next period. To keep the notations brief, we have dropped the household index $h$. The term $w$ denotes the maximum level of consumption admissible by the budget constraint if the household succumbs to temptation, that is,

$$
w=e+\sum_{i=1}^{I}\left(q^{i}+d^{i}\right) b^{i} .
$$

Let $R_{t+1}^{i}=\left(q_{t+1}^{i}+d_{t+1}^{i}\right) / q_{t}^{i}$ denote the gross return on asset $i$ between period $t$ and $t+1$. Then, for any asset $i \in\{1, \ldots, I\}$, the intertemporal Euler equation is given by

$$
u^{\prime}\left(c_{t}\right)+v^{\prime}\left(c_{t}\right)=\delta \mathrm{E}_{t}\left[u^{\prime}\left(c_{t+1}\right)+v^{\prime}\left(c_{t+1}\right)-v^{\prime}\left(w_{t+1}\right)\right] R_{t+1}^{i},
$$

where $u^{\prime}(\cdot)$ and $v^{\prime}(\cdot)$ denote the marginal commitment utility and the marginal temptation utility, respectively, $\mathrm{E}_{t}$ is a conditional expectation operator. More generally, the intertemporal Euler equation can be written as

$$
1=\mathrm{E}_{t} m_{t+1} R_{t+1},
$$

where, with a slight abuse of notation, $R_{t+1}$ denotes the gross return on a generic asset, and $m_{t+1}$ denotes the intertemporal marginal rate of substitution, also known as the stochastic discount factor (SDF), and is given by

$$
m_{t+1}=\frac{\delta\left[u^{\prime}\left(c_{t+1}\right)+v^{\prime}\left(c_{t+1}\right)-v^{\prime}\left(w_{t+1}\right)\right]}{u^{\prime}\left(c_{t}\right)+v^{\prime}\left(c_{t}\right)} .
$$


Our goal is to test the empirical importance of temptation and self-control in preferences. For this purpose, we follow Krusell and Smith (2003) and restrict our attention to a class of constant relative risk aversion (CRRA) utility functions, with the commitment utility and the temptation utility functions given by

$$
u(c)=\frac{c^{1-\gamma}}{1-\gamma}, \quad, v(c)=\lambda u(c),
$$

where $\gamma$ is the coefficient of relative risk aversion and $\lambda>0$ measures the strength of temptation. Under this specification, both the commitment utility $u$ and the temptation utility $v$ are concave, so that the household is risk-averse in consumption but risk-seeking in wealth (since $-v(w)$ is convex). In other words, the household exhibits more risk aversion when choosing among lotteries that promise immediate consumption rewards than when choosing among those that promise risky future returns. This pattern of risk attitudes is consistent with recent experimental evidence (e.g., Noussair and Wu, 2003). An immediate implication is that variations in consumption tend to make the household worse off, whereas variations in wealth (consisting of income and asset accumulations) tend to reduce the utility cost of resisting temptation and is thus desirable for the household. This feature has important implications for calculations of the welfare cost of business cycles, as we show in Section 6.

With the utility functions so parameterized, the SDF defined in (7) is given by

$$
m_{t+1}=\delta\left(\frac{c_{t+1}}{c_{t}}\right)^{-\gamma}\left[1-\frac{\lambda}{1+\lambda}\left(\frac{w_{t+1}}{c_{t+1}}\right)^{-\gamma}\right] .
$$

Clearly, without temptation, that is, with $\lambda=0$, the $\mathrm{SDF}$ reduces to

$$
m_{t+1}=\delta\left(\frac{c_{t+1}}{c_{t}}\right)^{-\gamma} .
$$

We are thus testing the hypothesis that the SDF is characterized by (9) against the alternative that it is described by (10).

Temptation and self-control give rise to the presence of the wealth-consumption ratio in the SDF. This complicates empirical estimation of the parameters of interest based on the intertemporal Euler equation, especially if there are measurement errors. Under some conditions, however, one can still obtain consistent estimates of the elasticity of intertemporal substitution (EIS) and the temptation parameter even in the presence of measurement errors. Inspecting the expression for the SDF in (9), we see that a sufficient condition for obtaining consistent estimates for these parameters is that the measurement errors in individual consumption and in wealth are multiplicative and proportional to each other (with a constant proportionality), and that they are independent of the true levels of consumption and wealth, independent of asset returns and the 
instruments. ${ }^{7}$ These conditions on the measurement errors appear quite stringent. This motivates our choice of estimating a log-linearized version of the Euler equation. ${ }^{8}$

For the purpose of obtaining a log-linearized Euler equation, we assume that the consumption growth rate and the wealth-consumption ratio are both stationary. ${ }^{9} \mathrm{~A}$ log-linear approximation to the SDF around the steady state is given by

$$
\ln \left(m_{t+1}\right)=\ln (\delta)-\ln (1+\phi)-\gamma \ln \left(\frac{c_{t+1}}{c_{t}}\right)+\gamma \phi\left[\ln \left(\frac{w_{t+1}}{c_{t+1}}\right)-\ln \left(\frac{w}{c}\right)\right]+\kappa_{t+1},
$$

where the term $\kappa_{t+1}$ includes the second or higher moments in consumption growth and the wealth-consumption ratio, and the parameter $\phi$ is given by

$$
\phi=\frac{\lambda}{(1+\lambda) \chi^{\gamma}-\lambda},
$$

with $\chi=w / c$ denoting the steady-state ratio of wealth to consumption. Using (6) and (11), we obtain an empirical version of the consumption Euler equation in the presence of temptation:

$$
\ln \left(\frac{c_{t+1}}{c_{t}}\right)=b_{0}+\sigma \ln \left(R_{t+1}\right)+\phi \ln \left(\frac{w_{t+1}}{c_{t+1}}\right)+\nu_{t+1},
$$

where the intercept term $b_{0}$ contains the constants and unconditional means of the second or higher moments of consumption growth, wealth-consumption ratio, and asset returns, and the error term $\nu_{t+1}$ summarizes expectation errors and approximation errors (i.e., deviations of second or higher moments of the relevant variables from their unconditional means).

In the restricted model without temptation, the SDF reduces to $\ln \left(m_{t+1}\right)=\ln (\delta)-\gamma \ln \left(c_{t+1} / c_{t}\right)$. An empirical version of the intertemporal Euler equation is then given by

$$
\ln \left(\frac{c_{t+1}}{c_{t}}\right)=a_{0}+\sigma \ln \left(R_{t+1}\right)+\varepsilon_{t+1},
$$

where $\sigma=1 / \gamma$ is the EIS, the intercept term $a_{0}$ summarizes the constants and the unconditional mean of the second (or, in case of non-lognormal distributions, higher) moments of consumption growth and real asset returns, while the error term $\varepsilon_{t+1}$ contains expectation errors and

\footnotetext{
${ }^{7}$ For a similar argument in the context of estimating EIS alone (based on a CRRA utility function without temptation), see Attanasio and Weber (1995), Vissing-Jorgensen (2002), and Kocherlakota and Pistaferri (2004).

${ }^{8}$ The approach to estimating preference parameters based on log-linearized Euler equations is not without controversy. For a recent debate on some potential problems with and some main advantages of this approach, see the exchange between Carroll (2001) and Attanasio and Low (2004) (see also Ludvigson and Paxson, 2001). Despite its potential problems, the log-linear approach allows us to control the aggregation process, which is essential to capture the heterogeneity in individual preferences and to control for other aggregation biases and measurement errors. In the absence of a better approach to deal with aggregation biases and measurement errors, especially in a sample with a short time-series dimension of each individual household, as in the CEX survey, we view the log-linear approach as a useful compromise.

${ }^{9}$ Lettau and Ludvigson $(2001,2004)$ provide evidence that, in aggregate U.S. data, wealth and consumption are cointegrated so that this ratio is stationary.
} 
approximation errors. This equation forms the basis for estimating the EIS in the literature (e.g., Attanasio and Weber, 1989; Vissing-Jorgensen, 2002).

To test the empirical presence of temptation is thus equivalent to testing the Euler equation (13) under GP preferences against its alternative (14) under CRRA utility. We implement this empirical task by first obtaining joint estimates of the EIS parameter given by $\sigma$ and the temptation parameter represented by $\lambda$ using GMM, and then testing the null hypothesis that $\lambda=0$. To implement the GMM estimation, we use the log-linearized Euler equations (14) and (13) for the two alternative specifications of preferences, which, under rational expectations, lead to the moment conditions $E_{t}\left(Z_{t} \varepsilon_{t+1}\right)=0$ under the standard CRRA utility and $E_{t}\left(Z_{t} \nu_{t+1}\right)=0$ under the GP preferences, for any vector of variables $Z_{t}$ that lie in the information set of period $t .^{10}$ Note that, to obtain an estimate for $\lambda$ under GP preferences, we first estimate $\sigma$ and $\phi$ from (13), and then compute the point estimate of $\lambda$ from the relation

$$
\hat{\lambda}=\frac{\hat{\phi} \chi^{1 / \hat{\sigma}}}{1+\hat{\phi}\left(1-\chi^{1 / \hat{\sigma}}\right)},
$$

where a hatted variable denotes its point estimate. One can then obtain a $95 \%$ confidence interval for the estimate of $\lambda$ using the delta method. Clearly, the null hypothesis that $\lambda=0$ is equivalent to $\phi=0$.

\section{The Data}

In this section, we describe the data that we use to estimate the intertemporal Euler equations. The household-level data are taken from the Consumer Expenditure Survey (CEX) provided by the Bureau of Labor Statistics (BLS). In what follows, we present a general overview of CEX data (Section 3.1), discuss our procedure to construct a pseudo panel with synthetic birth-year cohorts of households (Section 3.2), describe our sample selection criteria (Section 3.3), and explain how to construct measures of consumption growth (Section 3.4), wealth-consumption ratio (Section 3.5), and asset returns (Section 3.6).

\footnotetext{
${ }^{10}$ One cannot rule out the possibility that deviations of the conditional second or higher moments in the Euler equations from their unconditional means might be highly persistent. This may make the use of lagged variables as instruments problematic in estimating Euler equations. Yet, Attanasio and Low (2004) show that, when utility is isoelastic and a sample covering a long time period is available, estimates from log-linearized Euler equations with varying interest rates are not systematically biased. A related issue is the control of measurement errors in the process of aggregation. When there are large enough cross-sectional observations, measurement errors in the linear terms tend to cancel out in the aggregation process, but those in the second or higher order terms contained in $\nu_{t+1}$ may not cancel, and may become even worse.
} 


\subsection{Overview}

The CEX survey has been conducted on an ongoing basis by the BLS in every quarter since 1980 . It is a representative sample of the universe of U.S. households. In each quarter, the BLS chooses about 5,000 households randomly according to the stratification criteria determined by the U.S. Census. The households are asked to report how much they have spent on a variety of goods and services in the previous three months. The 5,000 interviews are split more or less evenly over the three months of the quarter. Each household participates in the survey for five consecutive quarters, including one training quarter with no data recorded and four "regular" quarters, during which expenditure, income, and demographic information are recorded. Financial information is gathered only in the last interview, in which households report both the current stock of their assets and the flows over the previous 12 months. In each quarter, roughly one-fifth of the participating households are replaced by new households. Thus, CEX data are a rotating panel, which covers a relatively long time period and contains a considerable amount of demographic information.

The survey accounts for about $95 \%$ of all quarterly household expenditures in each consumption category from a highly disaggregated list of consumption goods and services. This gives CEX data a main advantage over other micro-panel data, such as the Panel Studies of Income Dynamics (PSID), which reports consumption expenditures for food only. ${ }^{11}$ CEX data would be particularly useful if preferences are nonseparable among different types of consumption goods and services in the theoretical model (e.g., Hall and Mishkin, 1982; Zeldes, 1989; Altug and Miller, 1990; Cochrane, 1991; Mankiw and Zeldes. 1991; Jacobs, 1999). Because of their broad coverage of consumption expenditures, CEX data have been widely used in the literature as an attractive alternative to aggregate macro data such as those in the National Income and Product Accounts (NIPA). For instance, CEX data have been used for the studies of a variety of issues, such as inequality (e.g.,Deaton and Paxson, 1994), consumption smoothing (e.g., Attanasio and Weber, 1995; Attanasio and Davis, 1996; Kruger and Fernandez-Vilaverde, 2004), and asset pricing (e.g., Vissing-Jorgensen, 2002), Brav, Constantinides, and Geczy, 2002; Cogley, 2002; Jacobs and Wang, 2004).

\subsection{The Synthetic Cohorts}

The short panel dimension of CEX data makes the use of direct panel techniques problematic. Since each individual household is interviewed only five times (including a training period), one

\footnotetext{
${ }^{11}$ Attanasio and Weber (1995) argue that food consumption is a poor measure of total consumption expenditures for investigating issues related to intertemporal substitution or asset pricing.
} 
would be seriously constrained by the time-series dimension in estimating Euler equations if individual household data were to be used. For this reason, we do not rely on individual household data. We follow instead a pseudo-panel approach proposed by Attanasio and Weber (1989, 1993, 1995), which exploits the repeated nature of the CEX surveys, and which takes its original root in Browning, Deaton and Irish (1985), Deaton (1985), and Heckman and Robb (1985). As new households from a randomly selected large sample of the U.S. population keep entering the survey, consumption by the sampled households contains information about the mean consumption of the group to which they belong. Thus, a relatively long time series can be constructed for each synthetic cohort, that is, a typical group defined by observable and relatively fixed characteristics.

The characteristic that we use to construct our synthetic cohorts is the birth years of household heads, as in Attanasio and Weber (1995). We define a birth-year cohort as a group of individuals who were born within a given five-year interval. We follow the households in each cohort through the entire sample period to generate a balanced panel. We exclude households whose heads were born after 1963 (younger than 21 in 1984) or before 1898 (older than 86 in 1984). The remaining households are assigned to 13 cohorts (i.e., 13 five-year intervals) based on their ages in 1984. We further narrow down our sample by excluding households whose heads are younger than 30 years or older than 55 years in 1984. We exclude those younger than 30 years because these households may not have had a chance to accumulate sufficient wealth, thus are likely to be liquidity constrained and, as a result, the Euler equations may not hold. We exclude those older than 55 years because these households are likely to retire before the end of our sample (the beginning of 2002), and households at retirement ages typically experience a discrete jump in consumption expenditures, and it is not clear whether or not the jump is consistent with the Euler equations. ${ }^{12}$ With these restrictions, we end up with five birth-year cohorts in our sample, with the ages of the household heads lying between 31 and 55 years in 1984 and between 48 and 72 years at the end of the sample.

We also report results based on a simple cohort technique, an approach used, for example, by Vissing-Jorgensen (2002). Under this approach, we pool the five birth-year cohorts into a single cohort, and compute the resulting cohort's consumption growth and wealth-consumption ratio by taking cross-sectional averages for each time period. This procedure results in a single time series.

\footnotetext{
${ }^{12}$ For a survey of the literature that documents the jump in consumption at retirement age and attempts to explain the jump, see, for example, Attanasio (1999). See Laitner and Silverman (2004) for a more recent explanation.
} 


\subsection{Limited Participation and Sample Selection Criteria}

The intertemporal Euler equation holds only for those households who participate in asset market transactions. But not all households participate. The importance of limited participation has been widely recognized in the literature (e.g., Mankiw and Zeldes, 1991; Brav, Constantinides, and Geczy, 2002; Cogley, 2002; and Vissing-Jorgensen, 2002, among others).

To recognize the importance of limited participation, we select a subsample of households who are classified as "asset holders" based on a similar set of criteria used by Cogley (2002) and Jacobs and Wang (2004). For a household's Euler equation between period $t$ and $t+1$ to hold, the household must hold financial assets at the beginning of period $t$, which corresponds to the beginning of the household's first interview period. Our first category of asset holders includes households who report positive holdings of "stocks, bonds, mutual funds, and other such securities" or "U.S. savings bonds" at the beginning of the first interview. ${ }^{13}$ Our second category of asset holders includes households who report positive contributions to "an individual retirement plan, such as IRA or Keogh" during the first two interview quarters (i.e, during period $t$ ). Our final category includes households who report receipts of positive dividend income or interest income during the first two interviews. Based on these criteria, we categorize $42 \%$ of households as asset holders. This number is comparable to that in Cogley (2002) (40\%) and in Haliassos and Bertaut (1995) (36.8\%), but somewhat larger than that in Jacobs and Wang (2004) (31\%) and in Mankiw and Zeldes (1991) (27.6\%), who all use a similar selection criterion but with a shorter sample in the time-series dimension.

To minimize the influence of measurement errors and other problems caused by poor quality of the data in our estimation, we apply some further restrictions to our sample in constructing the consumption growth data. First, we drop from our sample households who report non-positive real quarterly consumption. Second, as in Zeldes (1989) and Vissing-Jorgensen (2002), we drop outliers in the data for consumption growth rates, since these data may reflect reporting or coding

\footnotetext{
${ }^{13}$ This is the category of asset holders used by Vissing-Jorgensen (2002) in the context of estimating the EIS. As in Vissing-Jorgensen (2002), we use two pieces of information in the CEX survey to construct this category of asset holders. First, a typical household reports whether its holdings of the asset category have remained the same, increased, or decreased, compared to a year ago; second, a typical household reports the difference in the estimated market value of the asset category held by the household in the previous month with that held a year before. Thus, we infer that the household has a positive value of holdings of the asset category at the beginning of period $t$ if the household holds a positive amount of asset at the time of the interview and the asset value has either remained the same or decreased in the past year. If the household reports an increase in the asset value and the amount of the increase does not exceed the holdings at the time of the interview, we also infer that the household has a positive holding of the asset category at the beginning of period $t$.
} 
errors. Third, we drop the households with any missing interviews, since we cannot compute the semiannual consumption growth rate for these households. Fourth, we drop non-urban households, those residing in student housing, and those with incomplete income reports. Finally, we exclude from our sample households that report a change in the age of the household head between any two interviews by more than one year or less than zero. We do this to rule out the possibility of drastic changes in consumption behavior due to changes in household heads. In addition, starting in the first quarter of 1986, the BLS changed its household identification numbering system, leaving no information about the correspondence between the household identification numbers in 1985:Q4 and 1986:Q1. We have to drop some observations (seven monthly observations) because of this mismatching problem. A similar problem also occurred in 1996, and we have to drop four additional monthly observations.

\subsection{The Consumption Growth Rate}

We measure consumption by the sum of expenditures on nondurable goods and services. We construct a consumption basket for each household in the CEX survey based on the definition of nondurables and services in the NIPA. A typical consumption basket includes food, alcoholic beverages, tobacco, apparel and services, gasoline and auto oil, household operations, utilities, public transportation, personal care, entertainment, and miscellaneous expenditures. ${ }^{14}$ We deflate nominal consumption expenditures by the consumer price index for nondurables (unadjusted for seasonality), with a base period of 1982-1984.

To construct data for our estimation, we focus on semiannual frequencies, for two reasons. First, using lower frequency data helps mitigate problems caused by measurement errors, as argued by Vissing-Jorgensen (2002). Second, unique to our model with temptation, we need to construct wealth data for our estimation, and there is only one observation of wealth for each household in the CEX survey. Given the semiannual data that we construct, each household faces two decision periods: $t$ and $t+1$, which corresponds to the first and the second half of the year during which the household is interviewed.

The semiannual consumption growth rate is defined as

$$
\frac{c_{t+1}^{h}}{c_{t}^{h}}=\frac{c_{m+6}^{h}+c_{m+7}^{h}+c_{m+8}^{h}+c_{m+9}^{h}+c_{m+10}^{h}+c_{m+11}^{h}}{c_{m}^{h}+c_{m+1}^{h}+c_{m+2}^{h}+c_{m+3}^{h}+c_{m+4}^{h}+c_{m+5}^{h}}
$$

where $m$ refers to the first month that a household makes its consumption decision. Thus, $m+3$ is the month when the first interview is conducted, at which the household reports expenditures

\footnotetext{
${ }^{14} \mathrm{By}$ leaving out expenditures on durable goods, we implicitly assume that the utility function is separable in consumption of durables and of nondurables and services.
} 
incurred during the previous three months (i.e., $c_{m}^{h}, c_{m+1}^{h}$, and $c_{m+2}^{h}$ ), $m+6$ is the month for the second interview, at which the household reports consumption expenditures incurred during $m+3$, $m+4$, and $m+5$, and so on. For each household who has four complete interviews recorded, we obtain one observation of semiannual consumption growth rate. Given the rotating-panel feature of the CEX survey, we can construct a cohort-specific semiannual consumption growth rate for each month, which is the cross-sectional average of the consumption growth rates for households in the same cohort. The average consumption growth rate for a specific cohort $j$ is given by

$$
c g_{t+1}^{j}=\frac{1}{H_{t}^{j}} \sum_{h=1}^{H_{t}^{j}} \ln \left(\frac{c_{t+1}^{j h}}{c_{t}^{j h}}\right),
$$

where $H_{t}^{j}$ denotes the number of households in cohort $j$ in period $t$, and $c_{t}^{j h}$ denotes the period $t$ consumption of household $h$ in cohort $j$. Note that, if complete insurance against idiosyncratic risks were available, then all households would have identical consumption growth, and the average consumption growth rate would be identical to the growth rate of aggregate consumption per capita (aggregated in the spirit of NIPA). In general, if there are uninsurable idiosyncratic risks, consumption growth would not be identical across households, so that our measure of consumption growth rate as described in (17) would be more appropriate than the one obtained from aggregate data.

Table 1 presents some summary statistics of our measure of semiannual consumption growth, sorted by asset holder status and cohort groups. The table reveals a high degree of heterogeneity in consumption growth rates across households, suggesting the existence of important uninsurable consumption risks. ${ }^{15}$

\subsection{The Wealth-Consumption Ratio}

We now describe how we construct a theory-consistent measure of the wealth-consumption ratio.

In our model, a household's wealth $w_{t}$ is the maximum amount of resources available at the beginning of period $t$ for consumption if the household succumbs to temptation. It equals the

\footnotetext{
${ }^{15}$ Each time series has 199 monthly observations, covering the sample period from October 1983 to March 2001, where 11 monthly observations are missing because of the mismatching problem in the identification numbering system in 1986 and 1996. Note that the earliest interview period is the first quarter of 1984, when the households report consumption expenditures in the past three months, so that the time series of cohort-specific consumption growth rates starts in October 1983. The last interview period in our sample is the first quarter of 2002. Since a household's intertemporal consumption-savings decision shifts consumption between the first half year and the second half during the interview period, we need a whole year's consumption data to construct a consumption growth rate for a given household, so that the available consumption growth observations end by March 2001.
} 
sum of period $t$ income, including labor income and dividend income, and the market value of liquid financial assets available at $t$.

The CEX survey provides information on a household's asset holdings only for the last interview, at which the household reports both the current stock of assets and the flows during the previous 12 months. We retrieve asset holdings at the beginning of the period $t$ by subtracting the asset flows during the entire interview period from the end-of-interview asset stocks. This information helps pin down $\sum_{i=1}^{I} q_{t}^{i} b_{t}^{i h}$. But what is relevant for the intertemporal Euler equation is the wealth-consumption ratio at the beginning of period $t+1$. Thus, we need to calculate the value of $w_{t+1}^{h}$. For this purpose, we assume that the households follow a "buy-and-hold" strategy between their decision periods $t$ and $t+1$, so that the wealth at the beginning of period $t+1$ can be imputed based on reported income for $t+1$, the market value of the household's assets at the beginning of $t$, and the market return between $t$ and $t+1$. Specifically, we have

$$
w_{t+1}^{h}=y_{t+1}^{h}+\sum_{i=1}^{I} R_{t+1}^{i} q_{t}^{i} b_{t}^{i h},
$$

where $y_{t+1}^{h}=e_{t+1}^{h}+\sum_{i=1}^{I} d_{t+1}^{i} b_{t+1}^{i h}$ is the flow of reported income, consisting of labor income (i.e., endowment) and dividend income.

The asset categories that we use in constructing the wealth data include liquid asset holdings in the household's "checking accounts, brokerage accounts, and other similar accounts," "saving accounts," "U.S. savings bonds," and "stocks, bonds, mutual funds, and other such securities."16 To compute the total value of holdings of different types of assets, we assume a zero net return on the first category of assets (i.e., checking accounts, etc.); we use returns on the 30-day Treasury bills for the second and the third category of assets (i.e., savings and savings bonds); and finally, we use the New York Stock Exchange (NYSE) value-weighted returns for the last asset category (i.e., "stocks, bonds, mutual funds, and other such securities").${ }^{17}$

In addition to the value of financial assets, we need to have income data to construct our imputed wealth measure in (18). The CEX survey reports, for each interview, the "amount of total income after tax by household in the past 12 months." To calculate a household's semiannual

\footnotetext{
${ }^{16}$ We include here only liquid assets because the wealth in our model corresponds to the maximum amount of consumption if the household succumbs to temptation. The assets must have sufficient liquidity so that they can serve as "temptation." We have also examined a broader definition of asset holdings by including property values (mainly housing), and obtained very similar results (not reported).

${ }^{17}$ Clearly, we can obtain only one observation of asset value for each household during the entire interview period. But this does not present a problem for constructing our sample with semiannual data, since we can obtain only one observation of semiannual consumption growth rate for each household during the entire interview period, as discussed in Section 3.1, so we need only one observation for the wealth-consumption ratio for each household.
} 
income $y_{t}^{h}$ (i.e., income earned during the first half year of the household's interview period), we first divide the reported annual income at the time of each interview by four, and then add up the resulting quarterly incomes for the first and the second quarters in the interview period. Similarly, the income earned during the second half year of the household's interview period (i.e., $y_{t+1}^{h}$ ) is the sum of the household's average quarterly incomes for the third and the fourth interview quarters.

To get the wealth-consumption ratio for period $t$, we further need to construct the consumption data $c_{t}^{h}$ for household $h$ in period $t$. This is done by adding up the household's reported consumption expenditures during the first two interview quarters. To obtain $c_{t+1}^{h}$, we add up the household $h$ 's reported consumption expenditures during the last two interview quarters. We then divide the wealth measure by the consumption expenditures to obtain the relevant wealthconsumption ratio $w_{t+1}^{h} / c_{t+1}^{h}$. Finally, we average across households in a given synthetic cohort $j$ to obtain a time series of the cohort's wealth-consumption ratio

$$
\chi_{t+1}^{j}=\frac{1}{H_{t}^{j}} \sum_{h=1}^{H_{t}^{j}} \ln \left(\frac{w_{t+1}^{j h}}{c_{t+1}^{j h}}\right) .
$$

Note that because of the rotating-panel feature of the CEX survey, we can construct the semiannual wealth-consumption ratio for each month within the sample period for a given cohort. Table 2 presents some summary statistics of the wealth-consumption ratio, sorted by asset holder status and birth-year cohorts. Evidently, there is also a high degree of heterogeneity in the wealth-consumption ratios across households.

\subsection{Asset Returns and Some Timing Issues}

We use monthly NYSE value-weighted returns as a measure of nominal returns on risky assets and monthly 30-day Treasury bill returns as a measure of nominal returns on risk-free assets. To calculate real returns, we use the consumer price index for urban households as a deflator. As discussed above, we are able to construct only one observation of consumption growth and of wealth-consumption ratio for each household at the semiannual frequency. Thus, we need to convert the monthly asset returns into semiannual returns.

Obtaining semiannual asset returns based on monthly returns involves a somewhat subtle timing issue. By construction, the consumption growth rate is measured by the ratio of a household's total consumption during the last two quarters of interview to that during the first two quarters (see (16)). The consumption-savings decision can be made in any month during the first two quarters. If the intertemporal consumption-savings decision is made between the first and the seventh month, then the relevant semiannual asset return should be $R_{m+1} R_{m+2} \cdots R_{m+6}$, where $R_{m+1}$ denotes the gross real asset return between month $m$ and $m+1, R_{m+2}$ denotes the return 
between month $m+1$ and $m+2$, and so on. But if the intertemporal decision occurs between, for instance, the fourth and the tenth month, then the relevant semiannual return should be $R_{m+4} R_{m+2} \cdots R_{m+9}$. Our measure of the semiannual consumption growth rate does not distinguish between these two cases. We thus need to take a stand on what measure of the compounded returns is appropriate to serve our purpose of estimating the Euler equation. For simplicity and ease of comparison, we follow Vissing-Jorgensen (2002) and use the middle six months of relevant asset returns as a proxy for the asset returns of interest. In particular, we use $R_{m+3} \cdots R_{m+8}$ as a measure of semiannual asset returns.

Since the asset holders in our sample can hold a broad range of assets, we measure the asset returns in our estimation by an average between the real value-weighted NYSE returns and the real 30-day Treasury bill returns (i.e., joint returns). For comparison with the literature, we also examine an alternative measure of asset returns, which is the real value-weighted NYSE returns (i.e., stock returns).

\section{The Estimation Methods}

We estimate a log-linearized conditional Euler equation derived from our model using the generalized method of moments (GMM). We test the statistical significance of the temptation parameter by also estimating a restricted version of the model that does not allow for self-control preferences and thereby constructing a Wald test statistic. In what follows, we describe the equations to be estimated, the instrumental variables to be used, and the estimation and testing procedure.

\subsection{The Estimation Equations}

We estimate the log-linearized intertemporal Euler equation (13) augmented by a factor that controls for family size and by 12 monthly dummies that adjust for seasonality. In particular, the estimation equation for a particular cohort $j$ that consists of $H_{t}^{j}$ households in period $t$ is specified as

$$
c g_{t+1}^{j}=\sigma \ln \left(R_{t+1}\right)+\phi \chi_{t+1}^{j}+\alpha \frac{1}{H_{t}^{j}} \sum_{h=1}^{H_{t}^{j}} \Delta \ln F_{t+1}^{j h}+\sum_{m=1}^{12} \delta_{m} D_{m}+\mu_{t+1}^{j},
$$

where $\sigma$ is the EIS, the $D$ 's are monthly dummies, and $\Delta \ln F_{t+1}^{j h}$ is the the cross-sectional average of log changes in the households' family size. The variables $c g_{t+1}^{j}$ and $\chi_{t+1}^{j}$, to reiterate, are respectively the consumption growth rate and the wealth-consumption ratio for cohort $j$. The coefficients in front of the monthly dummies (i.e., the $\delta$ 's) are functions of the subjective discount factor, the unconditional mean of the wealth-consumption ratio, and the conditional second or 
higher moments of the log asset returns, log consumption growth, and log wealth-consumption ratio.

A distinct feature of self-control preferences is that an individual who is more susceptible to temptation has incentive to hold more commitment assets, that is, assets that cannot be easily re-traded (e.g., Gul and Pesendorfer, 2004b). One form of such assets is education (e.g., Kocherlakota, 2001). To capture the preference for commitment, and thereby to distinguish self-control preferences from other preference specifications such as habit formation (e.g., Constantinides, 1990) or non-expected utility (e.g., Epstein and Zin, 1989, 1991), we include an interaction term in the regression between the wealth-consumption ratio and an education dummy. The education dummy takes a value of one if the head of a household has a bachelor's degree or higher level of education, and zero otherwise. Specifically, we assume that the temptation parameter is a function of the education dummy (denoted by "EDUC"), so that

$$
\phi=\phi_{0}+\phi_{1} E D U C
$$

Substituting this expression for $\phi$ in (20), we obtain

$$
\begin{gathered}
c g_{t+1}^{j}=\sigma \ln \left(R_{t+1}\right)+\phi_{0} \chi_{t+1}^{j}+\phi_{1} \frac{1}{H_{t}^{j}} \sum_{h=1}^{H_{t}^{j}} E D U C^{j h} \times \ln \left(\frac{w_{t+1}^{j h}}{c_{t+1}^{j h}}\right) \\
+\alpha \frac{1}{H_{t}^{j}} \sum_{h=1}^{H_{t}^{j}} \Delta \ln F_{t+1}^{j h}+\sum_{m=1}^{12} \delta_{m} D_{m}+\mu_{t+1}^{j}
\end{gathered}
$$

where $E D U C^{j h}$ is an education dummy for household $h$ in cohort $j$.

The error term $\mu_{t+1}^{j}$ in these regression equations consists of expectation errors in the Euler equation and measurement errors in log consumption growth and log wealth-consumption ratio. It is also possible that the conditional second or higher moments contained in the $\delta$ 's are not constant, in which case, the $\delta$ terms capture the unconditional means of the second or higher moment terms, and the error term $\mu_{t+1}^{j}$ contains the deviations of these higher moments from their unconditional means.

\subsection{The Instrumental Variables}

An appropriate instrumental variable should be correlated with the explanatory variables including asset returns and the wealth-consumption ratio, but uncorrelated with the error term $\mu_{t+1}$. There are three types of errors in $\mu_{t+1}$, including expectation errors, approximation errors, and measurement errors. Under rational expectations, the expectation errors in $\mu_{t+1}$ are uncorrelated with variables in the information set of period $t$. For simplicity, we assume that the second or higher moment terms of the relevant variables in the estimation equations (20) and (22) are 
either constant or uncorrelated with variables in the information set of period $t$. Under these assumptions, any variable dated $t$ or earlier can serve as an appropriate instrument if there are no measurement errors. However, since we use CEX data, we need to confront issues related to measurement errors in the consumption growth rate and the wealth-consumption ratio when we select our instruments.

The instruments that we use for the asset returns include (i) a log dividend-price ratio measured by the ratio of dividends paid during the previous 12 months to the current-period S\&P 500 index price, (ii) lagged, log real value-weighted NYSE returns, and (iii) lagged, log real 30-day Treasury bill returns. All these financial variables are known to be good predictors of real stock returns and Treasury bill returns. ${ }^{18}$ Some caution needs to be applied in constructing the lags. A decision period in our model is one-half of a year, while the time-series variables for our estimation are of monthly frequencies. The consumption growth rate of a given cohort for adjacent months contains overlapping months and thus overlapping expectation errors. For this reason, the expectation error component of $\mu_{t+1}$ may be autocorrelated. To ensure that the instruments are uncorrelated with the error term, we use the compounded return $R_{m-5} R_{m-4} \cdots R_{m}$ as the lagged asset returns in our set of instrumental variables.

The instrument that we use for the wealth-consumption ratio is the lagged wealth-income ratio (i.e., $\left.\ln \left(w_{t} / y_{t}\right)\right)$. Since our measure for wealth $w_{t+1}$ is constructed under a "buy-and-hold" assumption (see (18)), it should be correlated with lagged wealth $w_{t}$. In the case where an interaction term between the wealth-consumption ratio and the education dummy is included as an explanatory variable, we use an interaction term between the lagged wealth-income ratio and the education dummy as an additional instrument. ${ }^{19}$

Table 3 reports the first-stage regression of the wealth-consumption ratio on the instrumental variables. The table reveals that the lagged wealth-income ratio is highly correlated with the wealth-consumption ratio, with regression coefficients significant at the $1 \%$ level under both the simple-cohort specification and the synthetic cohort approach.

\footnotetext{
${ }^{18}$ The financial time series here are downloaded from the Center for Research of Security Prices (CRSP).

${ }^{19}$ To the extent that measurement errors in wealth are serially uncorrelated, the lagged wealth-income ratio should be an appropriate instrument. Motivated by concerns that measurement errors might be serially correlated, we also estimated a Euler equation without using the lagged wealth-income ratio as an instrument, and we obtained similar results (not reported). Note that we use the lagged wealth-income ratio instead of the lagged wealth-consumption ratio as an instrument, since the latter would be correlated with measurement errors in the consumption growth rate.
} 


\subsection{The Estimation and Testing Procedure}

We estimate the EIS and the temptation parameter using GMM with an optimal weighting matrix. In our estimation, we explicitly account for autocorrelations of the $\mathrm{MA}(6)$ form and for heteroscedasticities of arbitrary forms in the error term. Autocorrelations in the error term may arise from the overlapping nature of consumption growth and thus of expectation errors, and heteroscedasticities may be present because the size of the cohort cells may vary over time.

We estimate our model based on the birth-year cohort approach proposed by Attanasio and Weber (1995). Our birth-year cohorts consist of five-year intervals, and we have five birth-year cohorts and thus five cohort-specific time series for each variable in the estimation equation. For comparison, we also estimate our model based on a simple-cohort approach, under which we obtain a single time series for each variable of interest by taking the cross-sectional average of the relevant variable at the household level across all households classified as asset holders.

To test the statistical significance of the presence of temptation, we follow two steps. First, we estimate the unrestricted model described by (20) or (22). Second, we estimate a restricted model by imposing $\phi=0$ (or $\phi_{0}=\phi_{1}=0$ if the interaction term is included). Under this restriction, we are estimating a standard Euler equation with CRRA utility. We test the null hypothesis that $\phi=0$ using a Wald statistic obtained as the ratio of the minimized quadratic objective in the restricted model to that in the unrestricted model, adjusted by the sample size and the degree of freedom. In the case where the interaction term is included in the estimation, we test the joint null hypothesis that $\phi_{0}=0$ and $\phi_{1}=0$. The test statistic has a $\chi^{2}$ distribution with a degree of freedom equal to the number of restrictions.

\section{The Results}

The results of the GMM estimations of the log-linearized model of equation (20) and (22) are shown in Table 4. We report the estimated values of the parameters of interest under both the simple-cohort approach and the synthetic-cohort panel specification.

The first three columns (1)-(3) in Table 4 present the estimates with a single time series constructed by following the simple-cohort technique. The asset returns used here are a simple average between the real value-weighted NYSE returns and real 30-day Treasury bill returns (i.e., joint returns). ${ }^{20}$ Column (1) reports the estimated value of the EIS in the model without temptation (i.e., $\phi=0$ ). The point estimate for EIS here is $\hat{\sigma}=0.516$, with a standard error

\footnotetext{
${ }^{20}$ We obtained similar results under the simple-cohort approach when we used stock returns instead of joint returns as a proxy for asset returns (not reported).
} 
of 0.499. The estimated EIS is not statistically significant, although one cannot reject the overidentification restrictions based on Hansen's J statistic. Column (2) reports the estimated values for $\sigma$ and $\phi$ in the model with temptation, but without the interaction term between education and the wealth-consumption ratio. The point estimate for $\sigma$ increases to 0.730 , which remains insignificant, with a standard error of 0.340 . The point estimate for $\phi$ is 0.023 , with a standard error of 0.023. Similar to the model without temptation, one cannot reject the over-identification restrictions based on the $\mathrm{J}$ statistic. Yet, one cannot reject the null hypothesis that $\phi=0$ based on the Wald statistic with a $p$ value of 0.55 . Column (3) reports the results when the interaction term between education and the wealth-consumption ratio is included. The point estimate for the EIS is lowered to 0.440 and is statistically insignificant. A notable feature is that, when we allow for the interaction term to capture the temptation parameter for individuals with high levels of education, the point estimate for the temptation parameter in this subgroup of individuals with high levels of education is much larger than its population counterpart: it increases by an order of magnitude from 0.023 to 0.237 . To the extent that education is a form of commitment assets, this result is consistent with the model's implication that a tempted individual has a preference for commitment. A problem with the estimates obtained under the simple-cohort approach is that the estimates are insignificant, and one cannot reject the null that the temptation parameter is zero. However, the rejection of the presence of temptation, as well as the inaccurate estimates of the EIS and the temptation parameter, may simply reflect a small-sample problem associated with the simple-cohort approach.

The synthetic cohort approach based on birth-year cohorts does not share this problem. Columns (4)-(9) report the estimation results using the pseudo-panel data constructed based on birth-year cohorts. Here, instead of having a single time series, we have a pseudo panel of data consisting of five time series, corresponding to the five birth-year cohorts. The sample size is now 988 , close to five times as much as that under the simple-cohort technique. ${ }^{21}$

Columns (4)-(6) report the estimation and testing results using the joint returns as a proxy for asset returns. The point estimate for the EIS in the model without temptation is similar to that obtained under the simple-cohort specification. In the model with temptation but without the interaction term, the point estimate for the EIS is $\hat{\sigma}=0.905$, with a standard error of 0.430 ; and the point estimate for the temptation parameter is $\hat{\phi}=0.031$, with a standard error of 0.015 . When the interaction term is included, the point estimate for the EIS increases slightly to 0.999 with a standard error of 0.449 , the estimated coefficient on the wealth-consumption ratio is close

\footnotetext{
${ }^{21}$ In the pseudo panel, some birth-year cohort cells are empty, so that the total number of observations in the panel is slightly less than five times that under the simple-cohort approach.
} 
to zero and insignificant, and the estimated coefficient on the interaction term is 0.162 with a standard error of 0.089. Thus, similar to the case with a simple cohort, individuals with high levels of education also have a high estimated value of the temptation parameter. This result lends support to the presence of temptation and self-control in preferences. In contrast to the case with a simple cohort, the estimated values of the temptation parameter under the synthetic cohort approach are statistically significant. The Wald statistics and the associated $p$ values overwhelmingly rejects the null hypothesis that $\phi=0$ and the joint hypothesis that $\phi_{0}=0$ and $\phi_{1}=0$. In this sense, temptation and self-control preferences are indeed an empirically important feature that characterizes individuals' optimal intertemporal decisions.

To examine the robustness of the results, we also estimate and test the models using some other proxies for asset returns. Columns (7)-(9) report the results when we replace the joint returns by stock returns measured by the value-weighted NYSE returns. The estimates for the EIS, with or without temptation, are now notably smaller than those obtained using joint returns. In the presence of temptation, the EIS estimates are significant at the $5 \%$ level. The point estimates for the temptation parameter are quite close to those obtained using joint returns as a proxy for asset returns. The Wald test of model restrictions overwhelmingly rejects the null that the temptation parameter is zero. This, again, suggests the presence of temptation and self-control. ${ }^{22}$

\subsection{Further Evidence}

Under the Gul-Pesendorfer preferences, an individual who is more susceptible to temptation has incentive to hold more commitment assets, as these assets help reduce the cost of self-control. We exploit this theoretical implication in our empirical study of the GP preferences by including in our estimation equation an interaction term between the wealth-consumption ratio and an education dummy, as education is often viewed as a form of commitment assets (e.g., Kocherlakota, 2001). We find that the temptation parameter is larger for individuals who have received higher levels of education. This finding lends empirical support to the GP preferences.

In addition to education, there are other forms of commitment assets, such as pensions. In our empirical estimation, we include an interaction term involving an education dummy to capture the effects of commitment on intertemporal decisions. We do not include interactions with pensions

\footnotetext{
${ }^{22}$ In obtaining the estimates reported in Table 4, we use an aggregation approach that allows for the possibility of imperfect risk sharing among households (see Section 3). To examine the role of risk sharing, we have also estimated a version of the model with complete risk sharing, in which the consumption growth rate is measured by the growth rate of mean consumption and the wealth-consumption ratio is measured by the ratio of mean wealth to mean consumption. The point estimate for the temptation parameter $\phi$ is close to zero and insignificant. This result is consistent with what DeJong and Ripoll (2003) have obtained using NIPA data.
} 
because, while education levels are likely exogenous for intertemporal decisions, pensions may not be. Since an individual who is more susceptible to temptation should have incentive to hold more commitment assets, we should observe positive correlations between education and pension contributions.

Table 5 shows the patterns of pension contributions for individuals with different levels of education. In the whole sample of asset holders, about $35 \%$ of households report positive contributions to retirement accounts (Panel A). In the high-education group (i.e., those with a bachelor's or higher degree, as represented by our education dummy), the fraction of pension contributors is about 40\%, much higher than that in the low-education group (30\%) and that in the whole sample. Individuals who report positive contributions would save on average about $5.95 \%$ of income in retirement accounts, and the rate of retirement saving does not differ much between the two education groups $(6.00 \%$ vs. $5.90 \%)$. However, since individuals in the high-education group are more likely to contribute than those in the low-education group, the mean retirement saving rate in the high-education group is significantly higher $(2.44 \%$ vs. $1.77 \%)$.

These observations are consistent with the presence of temptation in intertemporal decisions, but the correlations between education and pension contributions might also be driven by some other factors. For instance, wealthy individuals are likely to have both high levels of education and high probabilities of retirement savings. To control for the wealth effect, we split the sample of households according to their wealth levels, and report the relation between education and pension contributions for each wealth group. Panels B-D in Table 5 reveal that, while wealthier individuals are more likely to contribute to pensions regardless of education levels, an individual with a higher level of education within each wealth group is more likely to save for retirement, just as in the whole sample. In particular, in the low-wealth group ( $\$ 25,000$ or below), $33 \%$ of households who hold a bachelor's or higher degree report positive contributions, compared to $23 \%$ for those with lower levels of education; in the mid-wealth group (between $\$ 25,000$ and $\$ 50,000$ ), educated individuals are also more likely to contribute, although the difference across the two education groups is slightly smaller (37\% vs. $31 \%$ ) than that in the low-wealth group; in the high-wealth group (above $\$ 50,000$ ), individuals with higher levels of education are again more likely to save for retirement ( $46 \%$ vs. $37 \%$ ). Thus, a general pattern stands out: individuals who spend more years in school are also more likely to contribute to retirement accounts, regardless of their wealth levels.

To summarize, we find that individuals with higher levels of education have a larger temptation parameter. Further, these same individuals are also more likely to contribute to pension funds. As both education and pension contributions may have commitment values, our findings lend 
empirical support to the theory that temptation and self-control is an important characteristic in intertemporal consumption-savings decisions.

\section{Some Applications}

The presence of temptation and self-control in preferences not only changes the form of the utility function, but also augments the asset-pricing kernel with the wealth-consumption ratio. Based on our estimates of the strength of temptation, we now examine the quantitative implications of this class of preferences for two issues: the equity premium and the welfare cost of business cycles.

\subsection{Equity Premium and the Hansen-Jagannathan Bound}

Let $R_{t}^{f}$ denote the gross return of a risk-free asset between period $t$ and $t+1$, and $R_{t+1}^{e}=R_{t+1}-R_{t}^{f}$ the excess return of risky assets. The risk-free return equals the inverse of the conditional mean of the SDF. That is,

$$
R_{t}^{f}=\frac{1}{E_{t}\left(m_{t+1}\right)} .
$$

Using this relation and the intertemporal Euler equation (6), we obtain the unconditional mean of the excess return

$$
\mathrm{E}\left(R^{e}\right)=-\frac{\operatorname{Cov}\left(m, R^{e}\right)}{\mathrm{E}(m)} .
$$

Let $\rho\left(m, R^{e}\right)$ denote the correlation coefficient between the SDF and the excess return and $\sigma(x)$ denote the standard deviation of a variable $x$. Using the relation that $\operatorname{Cov}\left(m, R^{e}\right)=$ $\sigma(m) \sigma\left(R^{e}\right) \rho\left(m, R^{e}\right)$ and the fact that $\rho\left(m, R^{e}\right) \leq 1$, we obtain from (24) the Hansen-Jagannathan (1991) (HJ) bound

$$
\frac{\left|E\left(R^{e}\right)\right|}{\sigma\left(R^{e}\right)} \leq \frac{\sigma(m)}{E(m)} \approx \sigma(\ln m),
$$

where, to obtain the last approximation, we have assumed a lognormal distribution of the SDF. Using (11), we obtain

$$
\frac{\left|E\left(R^{e}\right)\right|}{\sigma\left(R^{e}\right)} \leq \frac{\sigma(m)}{E(m)} \approx \sqrt{\sigma^{2}(\ln m)}=\gamma \sqrt{\sigma^{2}\left(\Delta \ln c_{t+1}\right)+\phi \Gamma},
$$

where $\Delta \ln c_{t+1}=\ln \left(c_{t+1} / c_{t}\right)$ denotes the log-growth rate of consumption, and

$$
\Gamma=\sigma\left(\ln \chi_{t+1}\right)\left[\phi \sigma\left(\ln \chi_{t+1}\right)-2 \sigma\left(\Delta \ln c_{t+1}\right) \rho\left(\Delta \ln c_{t+1}, \ln \chi_{t+1}\right)\right],
$$

where $\chi_{t+1}=w_{t+1} / c_{t+1}$ denotes the wealth-consumption ratio.

Clearly, without temptation and self-control, $\phi=0$ so that $\sigma(\ln m)=\gamma \sigma\left(\Delta \ln c_{t+1}\right)$ and the HJ bound takes the standard form

$$
\frac{\left|E\left(R^{e}\right)\right|}{\sigma\left(R^{e}\right)} \leq \frac{\sigma(m)}{E(m)} \approx \gamma \sigma\left(\Delta \ln c_{t+1}\right) .
$$


In the U.S. data, average excess return is about 0.8 percent and the standard deviation of the excess return is about 0.16 percent, so that the sharp ratio is about $\frac{\left|E\left(R^{e}\right)\right|}{\sigma\left(R^{e}\right)}=0.5$ (see, for example, Cochrane, 2005, p.456). Since the standard deviation of consumption growth in aggregate U.S. data is around 0.01 percent, the HJ bound requires risk aversion of an implausible magnitude: $\gamma$ has to be greater than or equal to 50! This illustrates a version of the equity premium puzzle first presented by Mehra and Prescott (1985).

A natural question is then: Does introducing temptation and self-control in the utility function help resolve the equity premium puzzle? Comparing the HJ bound under the GP preferences (26) and the one under the standard CRRA utility (28), we see that the answer depends on the sign and magnitude of the term $\phi \Gamma$, where $\Gamma$ is given by (27). As long as consumption growth and the wealth-consumption ratio are negatively correlated, we would have $\Gamma>0$ and things would be moving in the right direction. Indeed, in our sample of households who hold assets in the CEX data, the correlation coefficient between consumption growth and wealth-consumption ratio is about -0.09 , so that $\Gamma>0$. Now, what about the magnitude? To see how large the temptation parameter $\phi$ is required to meet the HJ bound, we first fix the risk aversion parameter at $\gamma=1$, which is close to its point estimate in the presence of temptation, as reported in Table 4 (column (5)). We then use the sample standard deviation of consumption growth given by $\sigma(\Delta \ln c)=0.04$, the standard deviation of logged wealth-consumption ratio given by $\sigma(\ln \chi)=0.39$, and a sample correlation of $\rho(\Delta \ln c, \ln \chi)=-0.09$ between these two variables to compute a lower bound for $\phi$ so that the HJ bound in (26) is satisfied, that is, $\gamma \sqrt{\operatorname{var}\left(\Delta \ln c_{t+1}\right)+\phi \Gamma} \geq 0.5$. It turns out that to satisfy the HJ bound requires $\phi>1.26$. In contrast, the point estimate for $\phi$ is about 0.03 , much lower than that required to satisfy the HJ bound. Figure 1 plots the combinations of $\gamma$ and $\phi$ that are required to meet the HJ bound (the solid line), along with our point estimates of these two parameters (the circle). Clearly, the point estimates lie far from the HJ bound. Thus, although the strength of temptation is empirically significant, allowing for temptation and self-control in utility does not seem to help explain the equity premium puzzle.

\subsection{Temptation and Welfare}

We now examine the quantitative implications of temptation preferences on the welfare cost of business cycles based on our estimated strength of temptation. Following Lucas (1987), we focus on a representative-agent economy, and we do not attempt to model the driving forces of the business cycle properties of consumption and wealth; instead, we assume that these variables 
follow the same stochastic processes as observed in U.S. data. ${ }^{23}$ We imagine the existence of a (black-box) model that is capable of generating exactly the same business cycle properties of consumption and wealth as in the data. In practice, we assume that the logarithm of the level of real consumption per capita follows a trend-stationary process,

$$
c_{t}=c+\mu t-\frac{1}{2} \sigma_{z}^{2}+z_{t}
$$

where $z_{t}$ is an i.i.d. white-noise process with mean 0 and standard deviation $\sigma_{z}$. We also make an assumption that the log-level of real wealth per capita follows a trend-stationary process,

$$
w_{t}=w+\mu t-\frac{1}{2} \sigma_{u}^{2}+u_{t}
$$

where $u_{t}$ is an i.i.d. white-noise process with mean 0 and standard deviation $\sigma_{u}$. To help exposition, we assume that $u_{t}$ and $z_{t}$ are independent processes. ${ }^{24}$ The assumption that consumption and wealth share a common trend is motivated by empirical evidence on the existence of a cointegration relation between the two variables in U.S. data (e.g., Lettau and Ludvigson, 2001, 2004). The terms $\sigma_{z}^{2} / 2$ and $\sigma_{u}^{2} / 2$ are subtracted from the log of consumption and the log of wealth to ensure that changes in the variances of the innovation terms are mean-preserving spreads on the corresponding levels.

In the spirit of Lucas (1987), we ask the following question: What would be the maximum welfare gains if all uncertainties in consumption and wealth are eliminated? To answer this question, we measure the welfare gains by the percentage increase in consumption that the representative household needs to be compensated in the economy with uncertainties specified in (29) and (30), so that the household would be indifferent between living in the stochastic economy and living in a hypothetical benchmark economy without uncertainties. We call this measure of welfare the "compensation consumption equivalence" (CCE). With some algebra, we can show that the CCE is given by

$$
\mathrm{CCE}_{1}=\exp \left(\frac{1}{2} \sigma_{z}^{2}-\frac{\lambda}{2(1+\lambda)} \sigma_{u}^{2}\right)-1
$$

for the case with $\gamma=1$ (i.e., the log utility), and by

$$
\mathrm{CCE}_{2}=\exp \left(\frac{\gamma}{2} \sigma_{z}^{2}\right)\left\{1+\frac{\lambda}{1+\lambda}\left(\frac{W}{C}\right)^{1-\gamma}\left[\exp \left(-\frac{\gamma(1-\gamma)}{2} \sigma_{u}^{2}\right)-1\right]\right\}^{\frac{1}{1-\gamma}}-1
$$

\footnotetext{
${ }^{23}$ One should view the analysis here as a first pass to a more ambitious investigation that takes into account potential effects of household heterogeneity and market incompleteness, among other frictions. For a survey of recent progress in this literature, see, for example, Barlevy (2004).

${ }^{24}$ Allowing for cross correlations between these processes does not change the qualitative results. A more ambitious exercise should consider general equilibrium interactions between consumption and wealth, which we leave for future research.
} 
for the general case with $\gamma \neq 1$.

Evidently, the welfare cost of business cycle fluctuations increases with consumption volatility (i.e., $\sigma_{z}^{2}$ ) and, if $\lambda>0$, decreases with wealth volatility (i.e., $\sigma_{u}^{2}$ ). Lucas's original calculation based on standard preferences without temptation suggests that the welfare costs of business cycles are likely small. Our calculation here suggests that, in the presence of temptation (i.e., $\lambda>0$ ), the costs would be even smaller. Further, depending on the volatility of wealth relative to that of consumption and on the strength of temptation, the welfare costs of fluctuations can even be negative!

It is clear that risk-averse individuals dislike fluctuations in consumption, so that an increase in consumption volatility raises the welfare cost of fluctuations. It is less transparent why the welfare cost decreases with wealth volatility in the presence of temptation. To understand this result, it helps to inspect the utility function (2). There, it is clear that, as wealth increases, the household needs to exert more efforts to resist the temptation of overconsumption, although it enables the household to afford more. Since the temptation utility with respect to wealth is concave, larger volatilities in wealth fluctuations tend to lower the expected temptation utility, and thus to reduce the efforts needed to resist temptation. In this sense, fluctuations in wealth provide some commitment value that increases welfare. This is why an increase in the variance of wealth tends to reduce the welfare costs, as revealed by the expressions in (31) and (32). These expressions also reveal that, as the strength of temptation measured by $\lambda$ increases, the welfare cost declines for given volatilities in consumption and wealth, as illustrated by Figure $2 .{ }^{25}$

A natural question is then: What is the quantitative size of the welfare costs of business cycle fluctuations in the U.S. economy? To answer this question, we need to calibrate the volatilities $\sigma_{z}$ and $\sigma_{u}$, the parameters $\gamma$ and $\lambda$, and the wealth-consumption ratio $W / C$. For the purpose of illustration, we calibrate the volatilities and the wealth-consumption ratio using two alternative sources of data. One is the aggregate time series of consumption, income, and asset holdings constructed by Lettau and Ludvigson (2001) based on NIPA data; and the other is CEX data. The trends in the data are removed by applying the Hodrick-Prescott filter (for CEX data, we also make seasonal adjustments before applying the HP filter). From NIPA data, we obtain $\sigma_{z}=0.008, \sigma_{u}=0.025$, and $W / C=6.1$. From CEX data, we obtain $\sigma_{z}=0.025, \sigma_{u}=0.039$, and $W / C=8.6$.

\footnotetext{
${ }^{25}$ The welfare costs in Figure 2 are calculated based on the assumption of log utility, with the average wealthconsumption ratios and the volatilities of consumption and wealth calibrated to NIPA data and CEX data, respectively, as we describe below.
} 
Given the average wealth-consumption ratio in our samples, we then calibrate the parameters $\gamma$ and $\lambda$ using our estimates for the EIS parameter $\sigma$ and the temptation parameter $\phi$, as well as the relation in (15). Our estimate for $\sigma$ (based on joint returns) suggests that $\gamma$ is close to 1 , so we set $\gamma=1$ as a benchmark value. Given the value of $\gamma$, a point estimate of 0.031 for $\phi$ implies that $\lambda=0.2849$ if NIPA data are used to construct the average wealth-consumption ratio, and $\lambda=0.4795$ if CEX data are used instead. These parameter values imply that $C C E=-0.0037$ percent for NIPA data and $C C E=0.0066$ percent for CEX data. These results suggest that the welfare costs of business cycle fluctuations are not only small but can even be negative with our estimated strength of temptation in preferences.

What does this finding say about stabilization policies? Lucas (1987) concludes from his welfare exercises that stabilization policies may improve social welfare, but they are far less important than policies that promote economic growth. Our results lend support to his view. Further, our results suggest that stabilization policies, especially those aiming at smoothing income and therefore wealth fluctuations, can be counterproductive, since fluctuations in income and wealth serve to reduce the efforts needed for individuals to resist temptation. In this sense, though fluctuations in consumption may reduce welfare, some fluctuations in income and wealth can be socially desirable and might not deserve to be targets of stabilization policies.

It is easy to generalize our welfare calculations to evaluate alternative stochastic consumption paths in the presence of temptation. Consider two stochastic equilibria in two economies characterized by

$$
\mathcal{E}=\left\{\mu, \sigma_{z}, \sigma_{u}\right\} \quad \text { and } \quad \mathcal{E}^{\prime}=\left\{\mu^{\prime}, \sigma_{z}^{\prime}, \sigma_{u}^{\prime}\right\}
$$

respectively, and denote

$$
\Delta \mu=\mu-\mu^{\prime}, \quad \Delta \sigma_{z}^{2}=\sigma_{z}^{2}-\sigma_{z}^{\prime 2}, \quad \Delta \sigma_{u}^{2}=\sigma_{u}^{2}-{\sigma_{u}^{\prime}}_{u}^{2}
$$

We then pose the following general question: What uniform percentage variation in consumption in $\mathcal{E}$ needs to be made so that the household would be indifferent between living in $\mathcal{E}$ and $\mathcal{E}^{\prime}$ ?

With some algebra, we can show that, in the case with log utility (i.e., $\gamma=1$ ), the answer to this question is given by

$$
\operatorname{SCE}\left(\mathcal{E}, \mathcal{E}^{\prime}\right)=\exp \left(\frac{\delta}{(1-\delta)(1+\lambda)} \Delta \mu+\frac{1}{2} \Delta \sigma_{z}^{2}-\frac{\lambda}{2(1+\lambda)} \Delta \sigma_{u}^{2}\right)-1
$$

where SCE (stochastic consumption equivalence) is our welfare measure, and $\delta$ is the subjective discount factor. ${ }^{26}$ Clearly, in the special case where $\mathcal{E}^{\prime}=\{\mu, 0,0\}$, that is, in the deterministic

\footnotetext{
${ }^{26}$ We have also obtained a corresponding expression for the more general case with $\gamma \neq 1$, but we omit it here to conserve space.
} 
economy without fluctuations and with the same trend growth rate as that in $\mathcal{E}$, the welfare expression would reduce to $C C E_{1}$ in (31). In general, the welfare cost of moving from one stochastic economy to another depends on the differences in trend growth rates, in consumption volatilities, and in wealth volatilities. The general conclusion is that, by moving from one economy to another, the welfare cost increases if the consumption volatility increases, the wealth volatility decreases, or the trend growth rate falls.

\section{Conclusion}

In a series of important contributions, Gul and Pesendorfer (2001, 2004a) have laid down a theoretical, axiomatic foundation for the representation of preferences that allows for temptation and self-control. One of the main attractions of the axiomatic approach is that such preference representation is time-consistent, and is thus suitable for studying optimal policies. Temptation and self-control preferences have many important implications on macroeconomic issues, such as social security reform, income tax reform, and a variety of asset-pricing issues (e.g., Krusell and Smith, 2003; Krusell, Kuruşçu, and Smith, 2002, 2003; DeJong and Ripoll, 2003; and the survey by Gul and Pesendorfer, 2004b). To assess with confidence the quantitative importance of such preferences for these prominent issues, one needs to get a sense about whether or not the presence of temptation and self-control in preferences is supported by data.

This paper provides a first attempt to estimate the strength of temptation and self-control using household-level data. We have presented a simple infinite-horizon consumption-savings model that allows, but does not require, temptation and self-control in preferences. We have shown that, in the presence of temptation and self-control, the asset-pricing kernel is a function of not only consumption growth, as in standard models with CRRA utility, but also the wealth-consumption ratio, a feature unique to the model with temptation and self-control preferences. Using individual household-level data on consumption and wealth from the U.S. Consumer Expenditure Survey, we have obtained statistically significant joint estimates of the elasticity of intertemporal substitution and the parameter measuring the strength of temptation and self-control. The use of household-level data allows us to take into account limited participation in asset market transactions, and our aggregation procedure allows for the possibility of uninsurable idiosyncratic risks. Our empirical results lend support to the presence of temptation and self-control in individuals' preferences.

To illustrate the economic significance of temptation preferences, we have recalculated the equity premium and the welfare costs of business cycle fluctuations based on our estimated strength 
of temptation. It turns out that the equity premium puzzle documented in the literature based on standard preferences is still a puzzle under temptation preferences. A somewhat surprising finding is that the presence of temptation further reduces the welfare cost of fluctuations, and can even make the welfare cost negative. This result arises because there are two offsetting forces that drive the welfare cost of business cycles. The first works through fluctuations in consumption, which tend to reduce welfare since individuals are risk-averse with respect to consumption, just as in the standard model without temptation. The second works through fluctuations in income and wealth, which tend to improve welfare since, in the presence of temptation, the utility of wealth enters negatively so that individuals are risk-seeking with respect to wealth. In this sense, some fluctuations in income and wealth can be socially desirable if individuals are exposed to temptation and costly self-control.

Our findings also have potential implications for asset-pricing issues. In the presence of temptation, the wealth-consumption ratio and the consumption growth rate for asset holders jointly determine the asset-pricing kernel. Thus, looking into this class of preferences may also help build a theoretical underpinning for empirical work that aims at forecasting future asset returns and for explaining the cross-sectional variations of asset returns based on the wealth-consumption ratio for asset holders. Of course, temptation preferences may also play a potentially important role in understanding some issues of great economic significance, especially on public finance issues, such as the optimal design of social security and taxation systems. Quantitative assessment of these issues are promising, as they have important implications on public policy. Doing so would certainly require reliable empirical estimates of the strength of temptation and self-control, and our work represents a first step toward this direction.

\section{References}

Altug, Sumru, and Robert A. Miller, 1990. Household Choices in Equilibrium. Econometrica $58(3), 543-570$.

Ameriks, John, Andrew Caplin, John Leahy, and Tom Tyler, 2004. Measuring Self-Control. NBER Working Paper No. W10514.

Angeletos, George-Marios, David Laibson, Andrea Repetto, Jeremy Tobacman, and Stephen

Weinberg, 2001. The Hyperbolic Consumption Model: Calibration, Simulation, and Empirical Evaluation. Journal of Economic Perspectives 15(3), 47-68.

Attanasio, Orazio P., 1999. Consumption. Chapter 11 of Handbook of Macroeconomics, Vol 1, J.B. Taylor and M. Woodford (ed), Elsevier Science B.V. 1999. 
Attanasio, Orazio P., and Steven J. Davis, 1996. Relative Wage Movements and the Distribution of Consumption. Journal of Political Economy 104(6), 1227-1262.

Attanasio, Orazio P., and Hamish Low, 2004. Estimating Euler Equations. Review of Economic Dynamics 7(2), 406-435.

Attanasio, Orazio P., and Guglielmo Weber, 1989. Intertemporal Substitution, Risk Aversion and the Euler Equation for Consumption. Economic Journal 99(395), Supplement: Conference Papers 59-73.

Attanasio, Orasio P., and Guglielmo Weber, 1993. Consumption Growth, the Interest Rate and Aggregation. Review of Economic Studies 60(204), 631-649.

Attanasio, Orazio P., and Guglielmo Weber, 1995. Is Consumption Growth Consistent with Intertemporal Optimization? Evidence from the Consumer Expenditure Survey. Journal of Political Economy 103(6), 1121-1157.

Barlevy, Gadi, 2004. The Cost of Business Cycles and the Benefits of Stabilization: A Survey. NBER Working Paper No. 10926.

Benhabib, Jess, and Alberto Bisin, 2005. Modelling Internal Commitment Mechanisms and SelfControl: A Neuroeconomic Approach to Consumption-Saving Decisions. Games and Economic Behavior 52(2), 460-492.

Bernheim, B. Douglas, and Antonio Rangel, 2002. Addiction and Cue-Conditioned Cognitive Processes. NBER Working Paper No. 9329.

Brav, Alon, George Constantinides, and Christopher Geczy, 2002, Asset Pricing with Heterogeneous Consumers and Limited Participation: Empirical Evidence. Journal of Political Economy 110(4), 793-824.

Browning, Martin, Angus Deaton, and Margaret Irish, 1985, A Profitable Approach to Labor Supply and Commodity Demands over the Life-Cycle. Econometrica 53(3), 503-543.

Campbell, John Y., and John H. Cochrane, 1999. By Force of Habit: A Consumption-Based Explanation of Aggregate Stock Market Behavior. Journal of Political Economy 107(2), 205251.

Carroll, Christopher D., 2001. Death to the Log-Linearized Consumption Euler Equation! (And Very Poor Health to the Second-Order Approximation), Advances in Macroeconomics 1(1), Article 6, http://www.econ.jhu.edu/people/ccarroll/death.pdf.

Cochrane, John H., 1991. A Simple Test of Consumption Insurance. Journal of Political Economy 99(5), 957-976.

Cochrane, John H., 2005. Asset Pricing. Princeton, NJ: Princeton University Press. 
Cogley, Timothy, 2002. Idiosyncratic Risk and the Equity Premium: Evidence from the Consumer Expenditure Survey. Journal of Monetary Economics 49(2), 309-334.

Constantinides, George M., 1990. Habit Formation: A Resolution of the Equity Premium Puzzle. Journal of Political Economy 98(3), 519-543.

Constantinides, George M., 2002. Rational Asset Prices. Journal of Finance 57(4), 1567-1591.

Deaton, Angus, 1985. Panel Data from Time Series of Cross-Sections. Journal of Econometrics 30(1-2), 109-126.

Deaton, Angus, and Christina Paxson, 1994. Intertemporal Choice and Inequality. Journal of Political Economy 102(3), 437-467.

DeJong, David, and Marla Ripoll, 2003. Self-Control Preferences and the Volatility of Stock Prices. Working Paper, University of Pittsburgh.

Della Vigna, Stefano, and M. Daniele Paserman, 2004. Job Search and Impatience. Working Paper, University of California, Berkeley.

Epstein, Larry G., and Stanley E. Zin, 1989. Substitution, Risk Aversion, and the Temporal Behavior of Consumption and Asset Returns: A Theoretical Framework. Econometrica 57(4), 937-969.

Epstein, Larry G., and Stanley E. Zin, 1991. Substitution, Risk Aversion, and the Temporal Behavior of Consumption and Asset Returns: An Empirical Analysis. Journal of Political Economy 99(2), 263-286.

Fang, Hanming, and Dan Silverman, 2004. Time Inconsistency and Welfare Program Participation: Evidence from the NLSY. Cowles Foundation Discussion Paper No. 1465, Yale University.

Gul, Faruk, and Wolfgang Pesendorfer, 2001. Temptation and Self-Control. Econometrica 69(6), 1403-1435.

Gul, Faruk, and Wolfgang Pesendorfer, 2004a. Self-Control and the Theory of Consumption. Econometrica 72(1), 119-158.

Gul, Faruk, and Wolfgang Pesendorfer, 2004b. Self-Control, Revealed Preference and Consumption Choice. Review of Economic Dynamics 7(2), 243-264.

Gul, Faruk, and Wolfgang Pesendorfer, 2005a. The Revealed Preference Theory of Changing Tastes. Review of Economic Studies 72(2), 429-448.

Gul, Faruk, and Wolfgang Pesendorfer, 2005b. Harmful Addiction. Review of Economic Studies (forthcoming).

Haliassos, Michael, and Carol C. Bertaut, 1995. Why Do So Few Hold Stocks? Economic Journal 105(432), 1110-1129. 
Hall, E. Robert, and Frederic Mishkin, 1982. The Sensitivity of Consumption to Transitory Income: Estimates from Panel Data on Households. Econometrica 50(2), 461-481.

Hansen, Lars P., Ravi Jagannathan, 1991. Implications of Security Market Data for Models of Dynamic Economies. Journal of Political Economy 99(2), 225-262.

Harris, Christopher, and David Laibson, 2001. Dynamic Choices of Hyperbolic Consumers. Econometrica 69(4), 935-957.

Heckman, James.J., and Richard Robb, 1985. Alternative Methods for Evaluating the Impact of Interventions. In James J. Heckman and Burton Singer (eds.), Longitudinal Analysis of Labor Market Data. Cambridge: Cambridge University Press.

Jacobs, Kris, 1999. Incomplete Markets and Security Prices: Do Asset-Pricing Puzzles Result from Aggregation Problems? Journal of Finance 54(1), 123-164.

Jacobs, Kris, and Kevin Q. Wang, 2004. Idiosyncratic Consumption Risk and the Cross Section of Asset Returns. Journal of Finance 59(5), 2211-2252.

Jagannathan, Ravi, and Narayana R. Kocherlakota, 1996. Why Should Older People Invest Less in Stocks Than Younger People? Federal Reserve Bank of Minneapolis Quarterly Review 20(3), $11-23$.

Kocherlakota, Narayana R., 2001. Looking for Evidence of Time-Inconsistent Preferences in Asset Market Data. Federal Reserve Bank of Minneapolis Quarterly Review 25(3), 13-24.

Kocherlakota, Narayana R., and Luigi Pistaferri, 2004. Asset Pricing Implications of Pareto Optimality with Private Information. Mimeo, Stanford University.

Krueger, Dirk, and Jesus Fernandez-Villaverde, 2004. Consumption over the Life Cycle: Facts from Consumer Expenditure Survey Data. Working Paper, University of Pennsylvania.

Krusell, Per, and Anthony A. Smith, Jr., 2003. Consumption-Savings Decisions with QuasiGeometric Discounting. Econometrica 71(1), 365-375.

Krusell, Per, Burhanettin Kuruşçu, and Anthony A. Smith, Jr., 2002. Time Orientation and Asset Prices. Journal of Monetary Economics 49(1), 107-135.

Krusell, Per, Burhanettin Kuruşçu, and Anthony A. Smith, Jr., 2003. Temptation and Taxation. Working Paper, Yale University.

Laibson, David, 1994. Self-Control and Savings. Ph.D. dissertation, MIT.

Laibson, David, 1996. Hyperbolic Discount Functions, Undersaving, and Savings Policy. NBER Working Paper No. 5635.

Laibson, David, 1997. Golden Eggs and Hyperbolic Discounting. Quarterly Journal of Economics $112(2), 443-477$. 
Laibson, David I., Andrea Repetto, and Jeremy Tobacman, 1998. Self-Control and Saving for Retirement. Brookings Papers on Economic Activity 1, 91-172.

Laibson, David I., Andrea Repetto, and Jeremy Tobacman, 2004. Estimating Discount Functions from Lifecycle Consumption Choices. Working Paper, Harvard University.

Laitner, John, and Dan Silverman, 2004. Estimating Life-Cycle Parameters from the RetirementConsumption Puzzle. Working Paper, University of Michigan.

Lettau, Martin, and Sydney Ludvigson, 2001. Consumption, Aggregate Wealth, and Expected Stock Returns. Journal of Finance 56(3), 815-849.

Lettau, Martin, and Sydney Ludvigson, 2004. Understanding Trend and Cycle in Asset Values: Reevaluating the Wealth Effect on Consumption. American Economic Review 94(1), 276-299.

Loewenstein, George, 1996. Out of Control: Visceral Influences on Behavior. Organizational Behavior and Human Decision Processes 65(3), 272-292.

Lucas, Robert J., 1978. Asset Prices in an Exchange Economy. Econometrica 46(6), 1429-1445.

Lucas, Robert J., 1987, Models of Business Cycles. Oxford: Basil Blackwell.

Ludvigson, Sydney, and Christina H. Paxson, 2001. Approximation Bias in Linearized Euler Equations. Review of Economics and Statistics 83(2), 242-256.

Mankiw, N. Gregory, and Stephen P. Zeldes, 1991. The Consumption of Stockholders and Nonstockholders. Journal of Financial Economics 29(1), 97-112.

Mehra, Rajnish, and Prescott, Edward C., 1985. The Equity Premium: A Puzzle. Journal of Monetary Economics 15(2), 145-161.

Noussair, Charles, and Ping Wu, 2003. Risk Tolerance in the Present and the Future: An Experimental Study. Managerial and Decision Economics (forthcoming).

Paserman, Daniele, 2004. Job Search and Hyperbolic Discounting: Structural Estimation and Policy Evaluation. Working Paper, Hebrew University.

Peleg, Bezalel, and Manahem E. Yaari, 1973. On the Existence of a Consistent Course of Action when Tastes are Changing. Review of Economic Studies 40(3), 391-401.

Rabin, Matthew, 1998. Psychology and economics. Journal of Economic Literature 36(1), 11-36.

Rubinstein, Ariel, 2003. "Economics and Psychology"? The Case of Hyperbolic Discounting. International Economic Review 44(4), 1207-1216.

Strotz, R.H., 1956. Myopia and Inconsistency in Dynamic Utility Maximization. Review of Economic Studies 23(3), 165-180.

Vissing-Jorgensen, Annette, 2002. Limited Asset Market Participation and the Elasticity of Intertemporal Substitution. Journal of Political Economy 110(4), 825-853. 
Zeldes, Stephen P., 1989. Consumption and Liquidity Constraints: An Empirical Investigation. Journal of Political Economy 97(2), 305-346. 
Table 1.

Summary Statistics for Consumption Growth

\begin{tabular}{|c|c|c|c|c|c|c|c|c|c|}
\hline & No. Obs & Mean & S.D. & Skew. & Kurt. & Min & $\operatorname{Max}$ & $1 \%$ & $99 \%$ \\
\hline \multicolumn{10}{|c|}{ Panel A: Individual Consumption Growth } \\
\hline ALL & 19060 & 0.010 & 0.305 & -0.017 & 5.240 & -1.575 & 1.605 & -0.805 & 0.825 \\
\hline Asset Holder & 8116 & 0.010 & 0.308 & -0.060 & 5.346 & -1.575 & 1.605 & -0.808 & 0.834 \\
\hline \multicolumn{10}{|c|}{ Panel B: Consumption Growth for Simple Cohort (single time series) } \\
\hline ALL & 199 & 0.010 & 0.044 & -0.097 & 3.140 & -0.109 & 0.123 & -0.093 & 0.115 \\
\hline Asset Holder & 199 & 0.011 & 0.061 & -0.214 & 2.732 & -0.157 & 0.143 & -0.147 & 0.137 \\
\hline \multicolumn{10}{|c|}{ Panel C: Birth-Year Cohort, $1949-1953$} \\
\hline ALL & 199 & 0.012 & 0.063 & -0.014 & 2.664 & -0.163 & 0.172 & -0.140 & 0.150 \\
\hline Asset Holder & 199 & 0.011 & 0.093 & -0.054 & 3.295 & -0.266 & 0.247 & -0.245 & 0.244 \\
\hline \multicolumn{10}{|c|}{ Panel D: Birth-Year Cohort, $1944-1948$} \\
\hline ALL & 199 & 0.008 & 0.070 & 0.249 & 2.925 & -0.153 & 0.222 & -0.119 & 0.209 \\
\hline Asset Holder & 199 & 0.013 & 0.100 & -0.323 & 3.926 & -0.408 & 0.252 & -0.201 & 0.242 \\
\hline \multicolumn{10}{|c|}{ Panel E: Birth-Year Cohort, 1939 - 1943} \\
\hline ALL & 199 & 0.007 & 0.081 & -0.057 & 2.947 & -0.217 & 0.217 & -0.204 & 0.199 \\
\hline Asset Holder & 199 & 0.019 & 0.130 & -0.089 & 4.090 & -0.465 & 0.469 & -0.318 & 0.328 \\
\hline \multicolumn{10}{|c|}{ Panel F: Birth-Year Cohort, $1934-1938$} \\
\hline ALL & 199 & 0.009 & 0.094 & 0.595 & 5.747 & -0.299 & 0.479 & -0.211 & 0.236 \\
\hline Asset Holder & 193 & 0.011 & 0.138 & 0.820 & 6.856 & -0.387 & 0.751 & -0.308 & 0.449 \\
\hline \multicolumn{10}{|c|}{ Panel G: Birth-Year Cohort, 1929 - 1933} \\
\hline ALL & 199 & 0.008 & 0.099 & -0.188 & 3.512 & -0.368 & 0.256 & -0.252 & 0.237 \\
\hline Asset Holder & 198 & 0.005 & 0.155 & -0.267 & 4.267 & -0.522 & 0.465 & -0.467 & 0.464 \\
\hline \multicolumn{10}{|c|}{ Panel H: Consumption Growth for All Birth-Year Cohorts (pooled synthetic panel) } \\
\hline ALL & 995 & 0.009 & 0.082 & 0.121 & 4.433 & -0.368 & 0.479 & -0.190 & 0.216 \\
\hline Asset Holder & 988 & 0.012 & 0.125 & 0.041 & 5.461 & -0.522 & 0.751 & -0.319 & 0.315 \\
\hline
\end{tabular}


Table 2.

Summary Statistics for Wealth-Consumption Ratio

\begin{tabular}{|c|c|c|c|c|c|c|c|c|c|}
\hline & No. Obs & Mean & S.D. & Skew. & Kurt. & Min & $\operatorname{Max}$ & $1 \%$ & $99 \%$ \\
\hline \multicolumn{10}{|c|}{ Panel A: Individual Wealth-Consumption Ratio } \\
\hline ALL & 19060 & 5.596 & 11.84 & 14.87 & 433.5 & -146.5 & 501.2 & 0 & 46.76 \\
\hline Asset Holder & 8116 & 9.021 & 17.09 & 10.96 & 225.7 & -146.5 & 501.2 & 0 & 74.50 \\
\hline \multicolumn{10}{|c|}{ Panel B: Wealth-Consumption Ratio for Simple Cohort (single time series) } \\
\hline ALL & 199 & 5.732 & 2.110 & 2.048 & 8.601 & 3.143 & 16.78 & 3.215 & 15.15 \\
\hline Asset Holder & 199 & 8.933 & 4.351 & 1.619 & 5.475 & 4.233 & 27.16 & 4.381 & 24.06 \\
\hline \multicolumn{10}{|c|}{ Panel C: Birth-Year Cohort, 1949 - 1953} \\
\hline ALL & 199 & 5.407 & 3.134 & 3.977 & 25.34 & 2.438 & 29.62 & 2.10 & 21.25 \\
\hline Asset Holder & 199 & 8.192 & 6.428 & 4.059 & 25.71 & 2.233 & 58.53 & 2.041 & 39.03 \\
\hline \multicolumn{10}{|c|}{ Panel D: Birth-Year Cohort, $1944-1948$} \\
\hline ALL & 199 & 5.544 & 2.561 & 2.396 & 11.33 & 2.397 & 20.14 & 2.772 & 17.58 \\
\hline Asset Holder & 199 & 8.420 & 5.442 & 2.378 & 10.11 & 0.236 & 34.09 & 1.651 & 27.00 \\
\hline \multicolumn{10}{|c|}{ Panel E: Birth-Year Cohort, 1939 - 1943} \\
\hline ALL & 199 & 5.914 & 3.683 & 4.190 & 32.80 & 2.494 & 38.46 & 2.575 & 16.33 \\
\hline Asset Holder & 199 & 9.397 & 8.558 & 4.472 & 30.70 & 2.945 & 77.74 & 3.231 & 36.54 \\
\hline \multicolumn{10}{|c|}{ Panel F: Birth-Year Cohort, $1934-1938$} \\
\hline ALL & 199 & 5.849 & 3.765 & 2.787 & 12.98 & 0.889 & 26.50 & 1.006 & 25.15 \\
\hline Asset Holder & 193 & 10.26 & 9.777 & 3.310 & 15.57 & 1.322 & 69.09 & 1.901 & 51.70 \\
\hline \multicolumn{10}{|c|}{ Panel G: Birth-Year Cohort, 1929 - 1933} \\
\hline ALL & 199 & 6.446 & 8.065 & 10.16 & 125.1 & 0.625 & 107.4 & 1.017 & 24.44 \\
\hline Asset Holder & 198 & 11.53 & 12.47 & 5.044 & 34.89 & 0.449 & 107.4 & 1.333 & 63.35 \\
\hline \multicolumn{10}{|c|}{ Panel H: Wealth-Consumption Ratio for All Birth-Year Cohorts (pooled synthetic panel) } \\
\hline ALL & 995 & 5.832 & 4.677 & 11.57 & 229.6 & 0.625 & 107.4 & 1.567 & 20.65 \\
\hline Asset Holder & 988 & 9.312 & 8.950 & 4.978 & 39.77 & 0.236 & 107.4 & 2.190 & 51.70 \\
\hline
\end{tabular}


Table 3.

First Stage IV Regressions of $\log \frac{w}{c}$ and educ $\times \log \frac{w}{c}$ on Instruments

\begin{tabular}{|c|c|c|c|c|}
\hline & \multicolumn{2}{|c|}{ Simple Cohort } & \multicolumn{2}{|c|}{ Synthetic Cohort Panel } \\
\hline & \multicolumn{4}{|c|}{ Variables being instrumented } \\
\hline & $\log \frac{w_{t+1}}{c_{t+1}}$ & educ $\times \log \frac{w_{t+1}}{c_{t+1}}$ & $\log \frac{w_{t+1}}{c_{t+1}}$ & educ $\times \log \frac{w_{t+1}}{c_{t+1}}$ \\
\hline \multirow[t]{2}{*}{$\log \frac{w_{t}}{y_{t}}$} & $0.993^{* * *}$ & $0.582^{* * *}$ & $0.760^{* * *}$ & $0.405^{* * *}$ \\
\hline & $(0.066)$ & $(0.106)$ & $(0.028)$ & $(0.066)$ \\
\hline \multirow{2}{*}{ educ $\times \log \frac{w_{t}}{y_{t}}$} & & -0.242 & & $-0.292^{* * *}$ \\
\hline & & $(0.149)$ & & $(0.089)$ \\
\hline \multirow[t]{2}{*}{ dividend/price } & $-0.186^{* * *}$ & $-0.140^{* * *}$ & $-0.250^{* * *}$ & $-0.197^{* * *}$ \\
\hline & $(0.031)$ & $(0.051)$ & $(0.025)$ & $(0.041)$ \\
\hline \multirow[t]{2}{*}{ lagged stock return } & 0.093 & 0.164 & 0.031 & 0.055 \\
\hline & $(0.098)$ & $(0.128)$ & $(0.099)$ & $(0.150)$ \\
\hline \multirow[t]{2}{*}{ lagged bond returns } & -1.172 & 1.278 & -0.577 & 1.97 \\
\hline & $(1.094)$ & $(1.557)$ & $(1.069)$ & $(1.571)$ \\
\hline \multirow[t]{2}{*}{$\Delta \ln ($ familysize $)$} & -0.338 & $-0.238^{*}$ & -0.328 & 0.227 \\
\hline & $(0.445)$ & $(0.584)$ & $(0.171)$ & $(0.386)$ \\
\hline \multirow[t]{2}{*}{ Constant } & $2.603^{* * *}$ & $1.330^{* * *}$ & $2.507^{* * *}$ & $1.224^{* * *}$ \\
\hline & $(0.038)$ & $(0.060)$ & $(0.034)$ & $(0.059)$ \\
\hline Observations & 199 & 199 & 988 & 988 \\
\hline$R^{2}$ & 0.83 & 0.49 & 0.70 & 0.18 \\
\hline
\end{tabular}

Note: ${ }^{*}, * *$, and ${ }^{* * *}$ stand for significant estimates at $10 \%, 5 \%$, and $1 \%$ level, respectively. Robust standard errors are reported in the parentheses. The set of instrumental variables also includes twelve monthly dummies (not presented in the table). Stock returns are real value-weighted NYSE returns. Bond returns are real 30-day Treasury bill returns. 
Table 4.

GMM Estimation of Log-Linearized Euler Equation with Self-Control Preferences

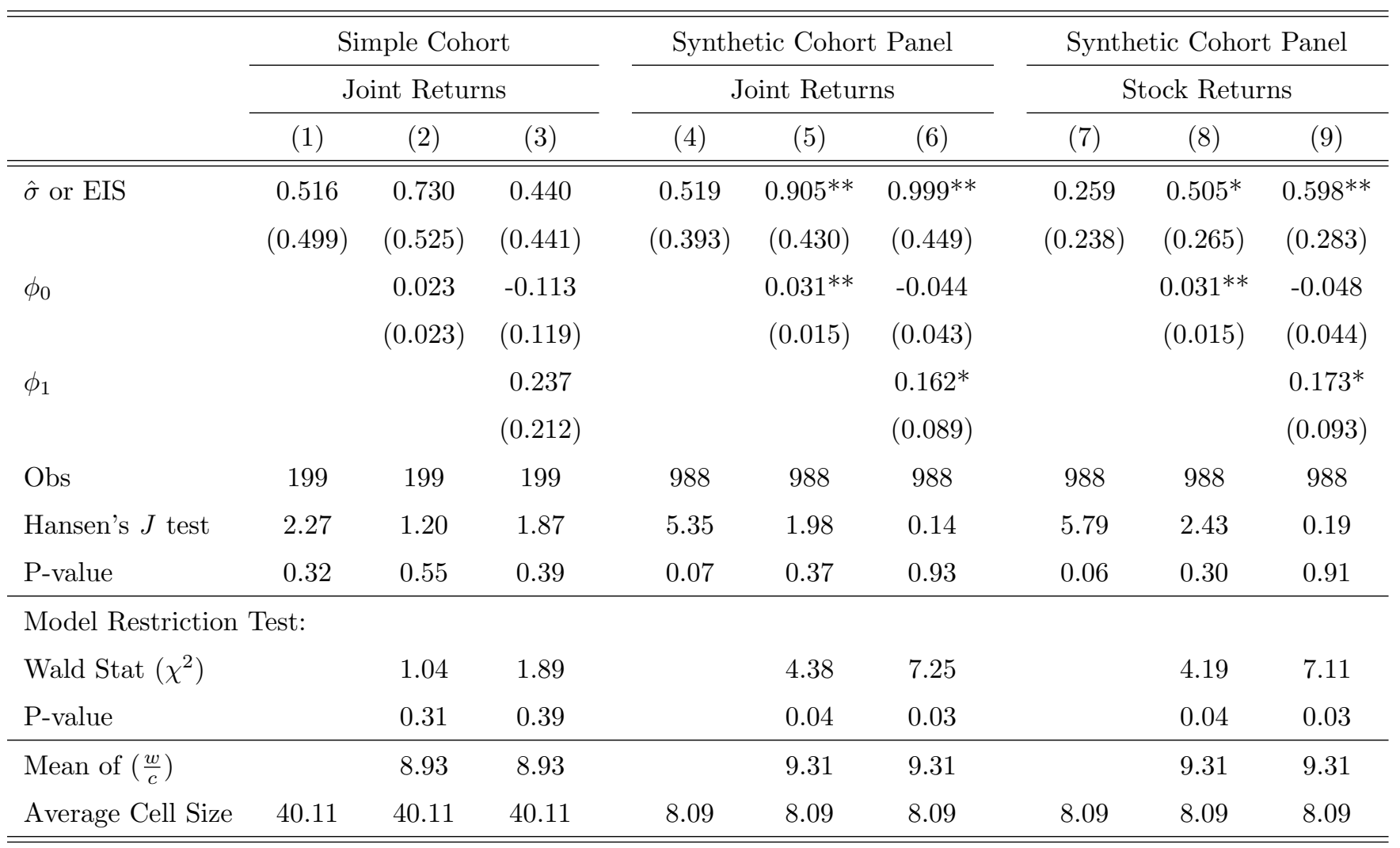

Note: $*{ }^{* *}$, and ${ }^{* *}$ stand for significant estimates at $10 \%, 5 \%$, and $1 \%$ level, respectively. Robust standard errors are reported in the parentheses. The regressions also include changes in family sizes and twelve monthly dummies as explanatory variables and instruments. The instrumental variables are those reported in Table 3. The null hypothesis for the model restriction test is that $\phi_{0}=0$ in the empirical specification without the interaction term between education and wealth-consumption ratio; and $\phi_{0}=\phi_{1}=0$ in the specification with the interaction term. The Wald statistic for the model restriction test has a $\chi^{2}$ distribution with a degree of freedom equal to the number of restrictions. 
Table 5.

Education Levels and Pension Contributions

\begin{tabular}{|c|c|c|c|c|c|}
\hline & \multicolumn{3}{|c|}{ Contribution to retirement account } & \multicolumn{2}{|c|}{ Mean contribution as share of income } \\
\hline & $>0$ & $=0$ & & all & $>0$ \\
\hline \multicolumn{6}{|c|}{ Panel A: All asset-holding households } \\
\hline Whole sample & $34.55 \%$ & $65.45 \%$ & $100 \%$ & $2.06 \%$ & $5.95 \%$ \\
\hline No bachelor degree & $30 \%$ & $70 \%$ & $100 \%$ & $1.77 \%$ & $5.90 \%$ \\
\hline Bachelor degree or higher & $40.59 \%$ & $59.41 \%$ & $100 \%$ & $2.44 \%$ & $6.00 \%$ \\
\hline Differences & & & & $-0.67 \% * * *$ & $-0.10 \%$ \\
\hline \multicolumn{6}{|c|}{ Panel B: Households with wealth less than $\$ 25,000$ (28.17\% of whole sample) } \\
\hline Subsample & $25.96 \%$ & $74.04 \%$ & $100 \%$ & $1.91 \%$ & $7.34 \%$ \\
\hline No bachelor degree & $23.32 \%$ & $76.68 \%$ & $100 \%$ & $1.71 \%$ & $7.32 \%$ \\
\hline Bachelor degree or higher & $33.11 \%$ & $66.89 \%$ & $100 \%$ & $2.45 \%$ & $7.40 \%$ \\
\hline Differences & & & & $-0.74 \% * * *$ & $-0.08 \%$ \\
\hline \multicolumn{6}{|c|}{ Panel C: Households with wealth between $\$ 25,000$ and $\$ 50,000$ ( $32.14 \%$ of whole sample) } \\
\hline Subsample & $33.36 \%$ & $66.64 \%$ & $100 \%$ & $1.62 \%$ & $4.86 \%$ \\
\hline No bachelor degree & $30.97 \%$ & $69.03 \%$ & $100 \%$ & $1.44 \%$ & $4.65 \%$ \\
\hline Bachelor degree or higher & $36.72 \%$ & $63.28 \%$ & $100 \%$ & $1.87 \%$ & $5.10 \%$ \\
\hline Differences & & & & $-0.43 \% * * *$ & $-0.45 \% *$ \\
\hline \multicolumn{6}{|c|}{ Panel D: Households with wealth greater than $\$ 50,000$ (39.69\% of whole sample) } \\
\hline Subsample & $41.62 \%$ & $58.38 \%$ & $100 \%$ & $2.51 \%$ & $6.04 \%$ \\
\hline No bachelor degree & $36.76 \%$ & $63.24 \%$ & $100 \%$ & $2.19 \%$ & $5.97 \%$ \\
\hline Bachelor degree or higher & $45.51 \%$ & $54.49 \%$ & $100 \%$ & $2.77 \%$ & $6.09 \%$ \\
\hline Differences & & & & $-0.58 \% * * *$ & $-0.12 \%$ \\
\hline
\end{tabular}




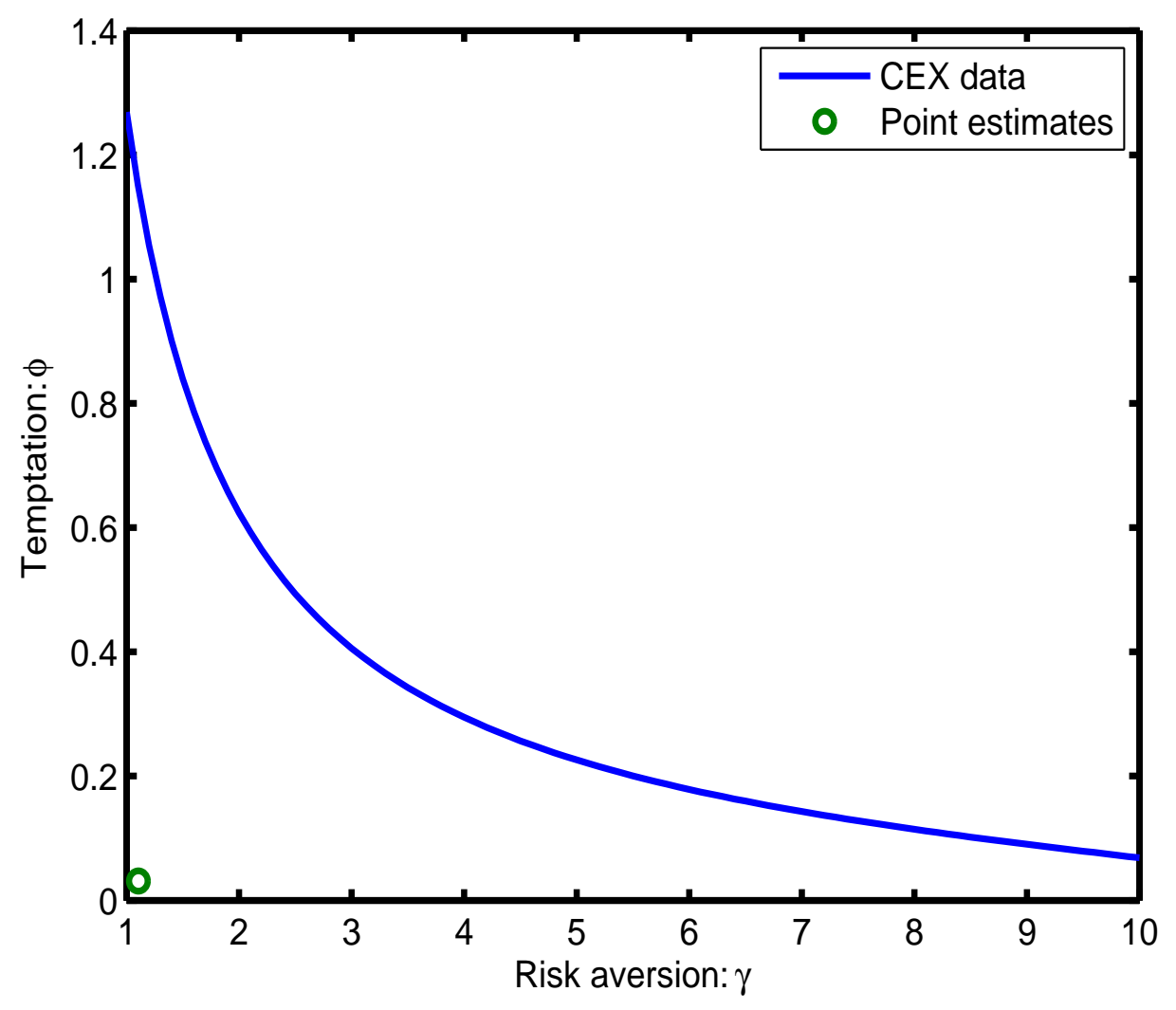

Figure 1:- Temptation and the Hansen-Jagannathan bound 


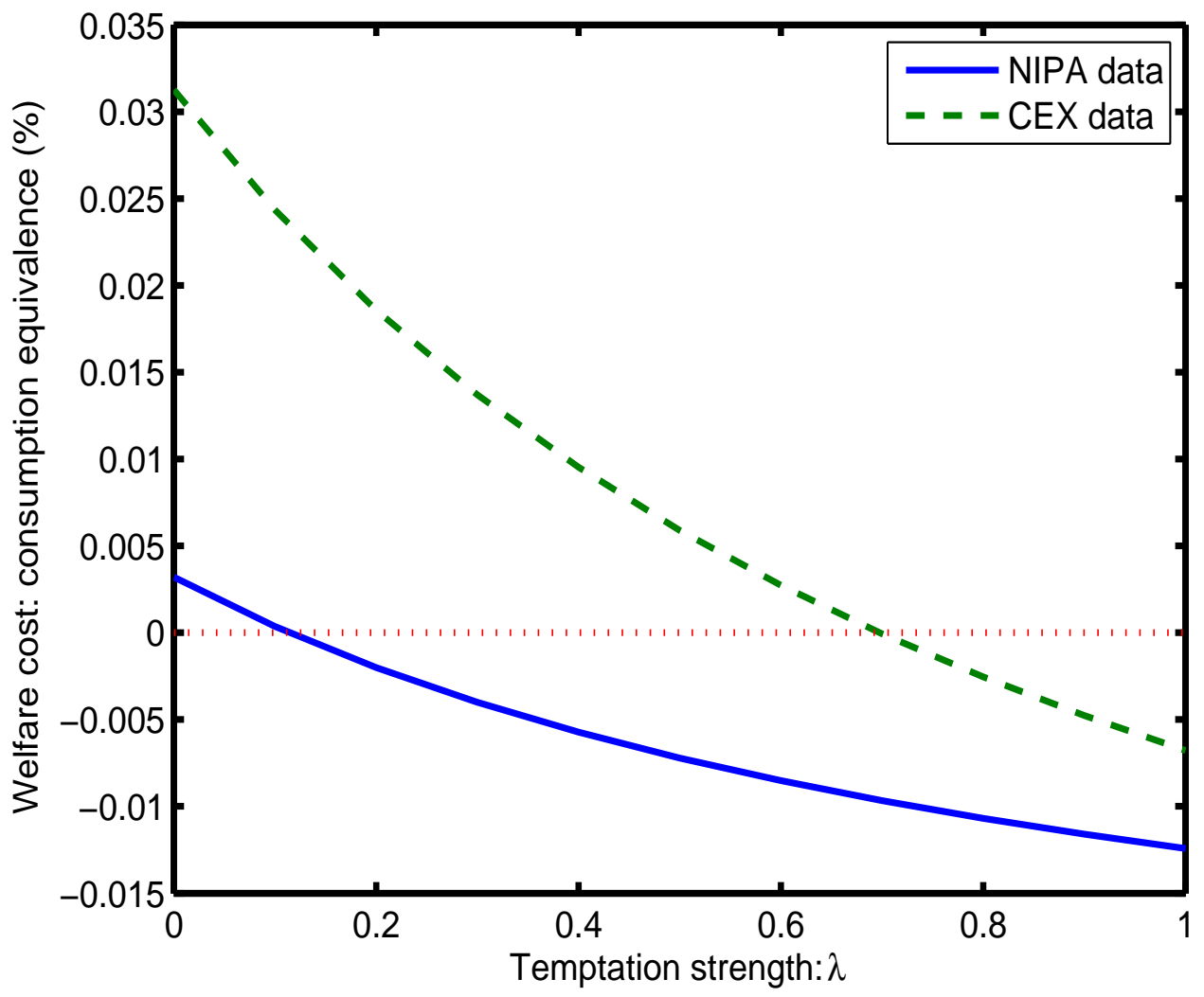

Figure 2:- Temptation and the welfare costs of business cycle fluctuations 